\title{
El Epipaleolítico en la vertiente mediterránea de la Península Ibérica: Investigaciones recientes
}

\author{
Marta MuÑIz PÉrez ${ }^{*}$
}

$\begin{aligned} \text { RESUMEN } & \text { ABSTRACT } \\ \text { El siguiente artículo constituye el } & \text { The following article constitutes } \\ \text { resumen del trabajo de investigación } & \text { the summary of the investigation } \\ \text { de doctorado presentado en el } & \text { work of doctorate presented at } \\ \text { Departamento de Prehistoria } & \text { the Departament of Prehistory } \\ \text { e Historia Antigua de la UNED. } & \text { and Ancient History (UNED). } \\ \text { Consiste en una recopilación } & \text { It consist on a bibliographical } \\ \text { bibliográfica acerca de los estudios } & \text { summary about the studies } \\ \text { realizados con posterioridad a la Tesis } & \text { accomplished at some point beyond } \\ \text { de J. Fortea (1973) "Los Complejos } & \text { the Thesis of J. Fortea (1973) } \\ \text { Microlaminares y Geométricos del } & \text { "Los Complejos Microlaminares } \\ \text { Epipaleolitico Mediterráneo Español» } & \text { y Geométricos del Epipaleolítico } \\ \text { referentes a los yacimientos } & \text { Mediterráneo Español» referring } \\ \text { catalogados como Epipaleolíticos o del } & \text { to the deposits catalogued as } \\ \text { Paleolítico Final de la vertiente } & \text { Epipalaeolithics or Final Palaeolithic } \\ \text { mediterránea de la Península lbérica. } & \text { of the East side of the Iberian } \\ \text { Tras una introducción geográfica e } & \text { Peninsula. After a geographical } \\ \text { historiográfica se propone una nueva } & \text { and historiographycal introduction } \\ \text { sistematizacióin de este periodo, } & \text { is proposed a new systematizing } \\ \text { teniendo en cuenta las dataciones } & \text { of this period, taking into account } \\ \text { radiocarbónicas realizadas en los } & \text { 14C dates series accomplished } \\ \text { distintos yacimientos. } & \text { in the different deposits. }\end{aligned}$

\section{INTRODUCCIÓN}

El estudio de la Prehistoria es complejo debido a que nos encontramos con una extrema escasez de datos. De hecho, casi tenemos que ir in-

* Becaria de F.P.I. Departamento de Prehistoria e Historia Antigua. Facultad de Geografía e Historia. UNED. 
ventando e ingeniando de dónde podemos sacar más datos que nos permitan acercarnos, aunque sólo sea tímidamente, a las formas de vida de nuestros ancestros, ya sea en su aspecto económico, social o, incluso, ideológico.

La Prehistoria es, por tanto, una ciencia oscura e inexacta, en la que tan sólo podemos aproximarnos a la realidad a partir del establecimiento de hipótesis que difícilmente podrán ser demostradas.

Dentro de la Prehistoria distinguimos diversos periodos, cuyos estudios y análisis se van enriqueciendo a partir de aquellas hipótesis indemostrables, pero sobre las que se sigue trabajando para acercarnos cada día un poco más a la verdad. Sin embargo, ya sea por tradición investigadora o por el interés que suscitan los distintos temas, no tenemos el mismo nivel de conocimiento sobre todos estos períodos. Probablemente sean los considerados como "transicionales" los más desconocidos. Tal es el caso del Epipaleolítico, claramente eclipsado por dos «momentos estrella», como son el Paleolítico Superior y el Neolítico, que ofrecen resultados mucho más espectaculares, aunque esto no significa que el primero sea menos interesante.

En el presente artículo queremos tratar el estado actual de la investigación sobre el tema del Epipaleolítico en la Vertiente Mediterránea de la Península lbérica a partir de la realización de una síntesis puramente bibliográfica ${ }^{1}$.

Para realizar este estudio hemos tomado como punto de partida la Tesis de J. Fortea (1973) sobre los Complejos Microlaminares y Geométricos del Epipaleolítico Mediterráneo Español, que significó en su día la puesta en valor e íntegra sistematización del Epipaleolítico Mediterráneo, constituyendo un trabajo excepcional que ordenó el caótico estado de la investigación en aquel momento. Sin embargo 29 años después (aunque publicada en 1973, la Tesis fue leída en 1969) encontramos un panorama muy distinto al planteado por este investigador: las secuencias halladas posteriormente no encajan, al menos de manera deseable, en aquella sistematización y la realidad de los datos actuales hace caer algunas asunciones tomadas entonces como ciertas.

El objetivo de este trabajo se centra, por tanto, en el análisis de los estudios sobre el Epipaleolítico de la Vertiente Oriental de la Península Ibérica realizados con posterioridad a aquella Tesis.

1 Este artículo constituye el resumen del Trabajo de Investigación de Tercer Ciclo presentado en el Departamento de Prehistoria de la Facultad de Geografía e Historia de la UNED en el año 1997. 
La síntesis de estos trabajos nos ha llevado a proponer una nueva sistematización del Epipaleolítico Mediterráneo en un intento de aunar aquéllos, más acorde con las investigaciones actuales y que se separa sensiblemente de las tradicionales.

En nuestro trabajo hemos preferido centrarnos en los momentos iniciales del Epipaleolítico, ya que consideramos que la transición al Neolítico merece por sí misma un tema de Tesis aparte. Los yacimientos con cerámica que pertenecen a las fases finales del Epipaleolítico Geométrico de Fortea (fases Cocina III y IV) exceden los límites aquí planteados. No podemos asegurar que se traten de momentos Neolíticos, ya que consideramos que no puede darse esta atribución económica y cultural por el simple hecho de haberse hallado unos fragmentos de cerámica entre el sedimento: sólo puede considerarse neolítica una manifestación económica caracterizada por la domesticación de animales y plantas. Pero ante la antigüedad de las excavaciones de muchos yacimientos y la falta de datos de tipo económico y dado que la cerámica suele aparecer ya en este estadio evolutivo, preferimos no llegar tan allá y prestar más atención a los momentos iniciales y medios del Epipaleolítico.

\section{EL ÁMBITO GEOGRÁFICO}

Consideramos el medio físico como motor fundamental del desarrollo de los grupos cazadores-recolectores. La interacción entre estos dos elementos, medio y grupo humano, es la primera causa de las transformaciones culturales sucedidas durante la Prehistoria. Sin embargo tampoco conviene exagerar este factor como se ha venido haciendo tradicionalmente para explicar el desarrollo del Epipaleolítico, ya que las investigaciones parecen demostrar que, al menos en la región objeto de estudio, no existió un cambio climático brusco.

El dominio geográfico elegido para este trabajo se corresponde con la zona Oriental de la Península, es decir, el dominio Mediterráneo. Está compuesta por una serie de estructuras que actúan como barreras territoriales naturales y de las que hemos destacado la Cordillera Pirenaica, la Depresión del Ebro, la Cordillera y Llanura Costera Catalana, el Sistema Ibérico, el Sureste y las Cordilleras Béticas (figuras 1 y 2).

La secuencia climática del Tardiglaciar y Postglaciar del Sureste Francés ha sido descrita por M. Escalón y otros autores. Este modelo es, hoy en día, el más generalizado. Sin embargo hay que ser cauto a la hora de extrapolarlo para la Región Mediterránea española, ya que los diversos 


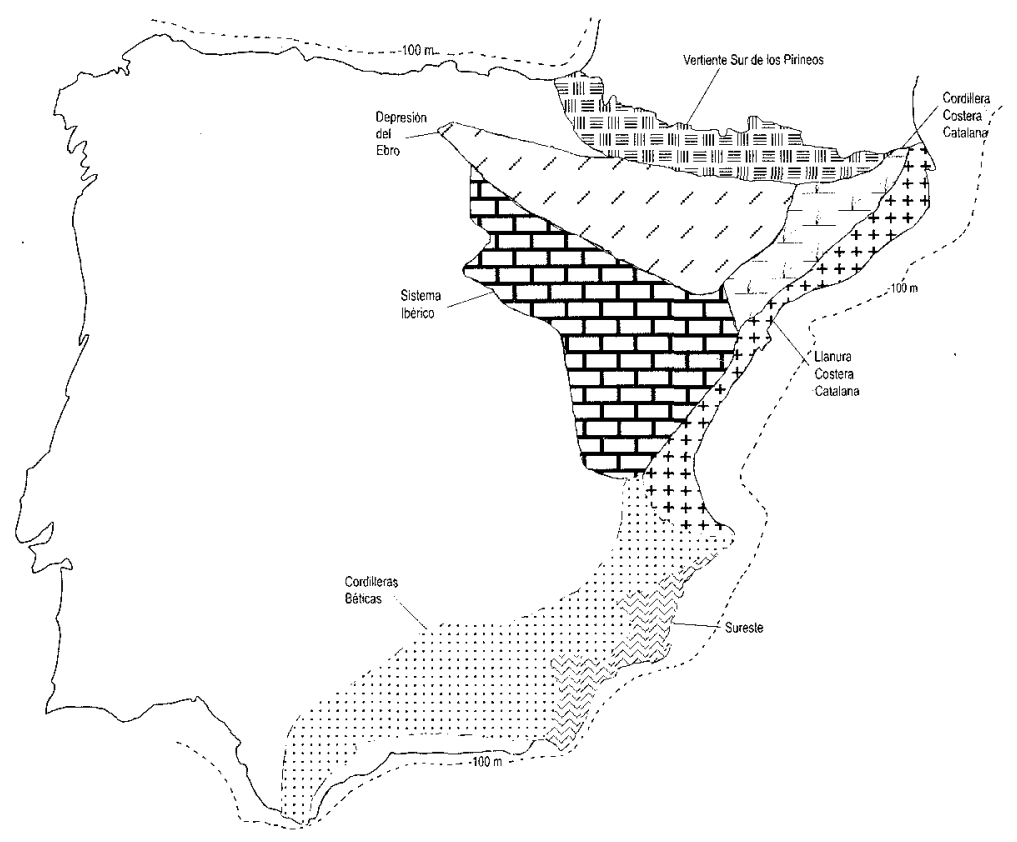

Figura 1. Distintas zonas geográficas tratadas en el trabajo.

estudios indican que esta región obedece a unas características especiales que hacen que su secuencia no siempre se corresponda con aquélla, en gran parte debido al mar Mediterráneo, que influye en el clima otorgándole una mayor aridez, torrencialidad y más altas temperaturas (Aura y Villaverde, 1995).

Los análisis antracológicos muestran la existencia de tres fases climáticas (Aura y Pérez Ripoll, 1995):

1. Tardiglaciar: características áridas y frías. Asociación de pino negral y enebro, pero se aprecia cierto aumento de especies termófilas, como Quercus.

2. Inicio del Holoceno o Postglaciar: más precoz en la región Mediterránea que en latitudes más septentrionales, donde se data en 8.000 BP. Se dan asociaciones más cálidas: roble-encina-coscoja y otras especies Mediterráneas encuentran su clímax durante el Atlántico, momento de expansión del Neolítico hacia el Mediterráneo Occidental.

3. A partir del 6.000 se aprecian los primeros bioindicadores de la acción humana sobre el territorio. 


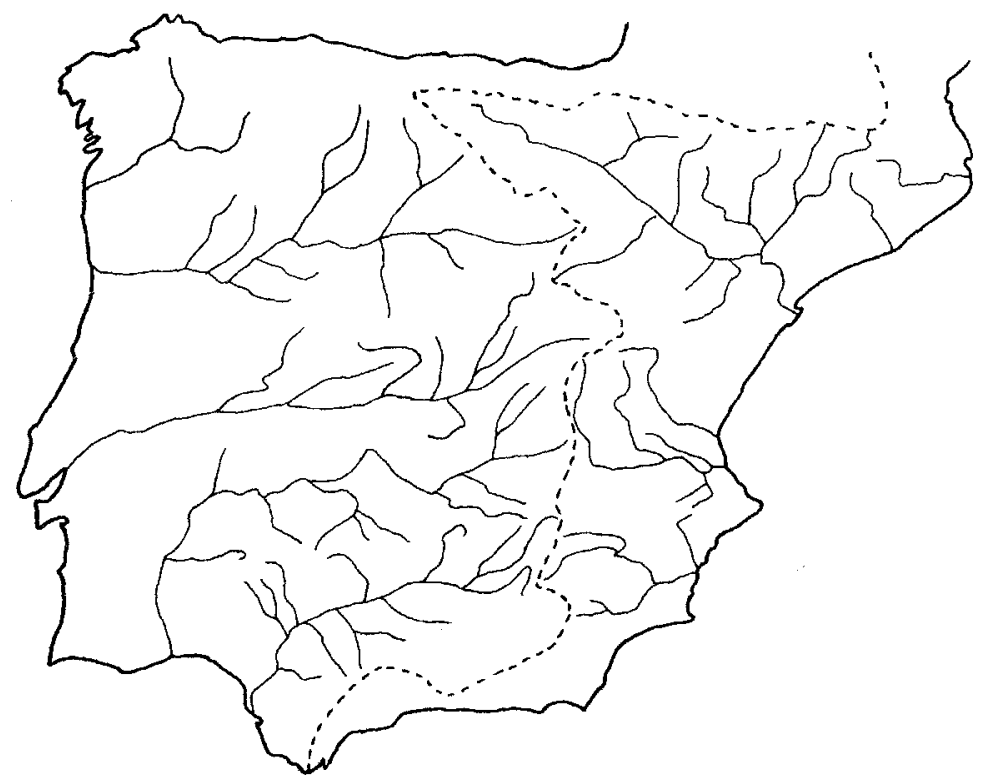

Figura 2. Red hidrográfica de la Península lbérica y gran divisoria de aguas Atlánticas y Mediterráneas (Gutiérrez Elorza, 1994).

El Tardiglaciar (13.000-11.000 BP) es un período de oscilaciones climáticas posterior al último máximo glaciar, con el que termina el Pleistoceno para dar paso al Holoceno. Se divide en los siguientes períodos:

\begin{tabular}{|l|l|}
\hline Dryas Reciente (III) & Pulsación fría y húmeda. \\
\hline Allerod & $\begin{array}{l}\text { Mejoría climática más importante del final del Pleistoceno. } \\
\text { Desarrollo del bosque. }\end{array}$ \\
\hline Dryas Medio (II) & Frío intenso y caídas de bloques generalizadas. \\
\hline Bölling & $\begin{array}{l}\text { Muy húmedo. Las crecidas fluviales vacían la mayoría de } \\
\text { los yacimientos asociados a depósitos de agua. }\end{array}$ \\
\hline Dryas Antiguo (I) & $\begin{array}{l}\text { Pulsación fría y árida. Hundimiento de las viseras de los } \\
\text { abrigos. }\end{array}$ \\
\hline
\end{tabular}

Durante el Tardiglaciar retroceden las glaciaciones continentales, aunque los casquetes sufren pequeños avances durante los períodos denominados Dryas, caracterizados por el frío y la estepización, mientras que Bölling y Alleröd responden a pulsaciones benignas, con desarrollo de coniferas y abedules. 
El paisaje típico del Tardiglaciar es de formaciones vegetales abiertas. En la zona norte y centro de la región Mediterránea española en los momentos más duros del Dryas se desarrollan las estepas de Artemisas, Poaceae y Quenopodiaceas. El Pino es el árbol más característico, y en menor frecuencia aparecen también Avellano, Abedul y Quercus. En la parte sur de la Península Ibérica durante el Dryas I aumentan los taxones estépicos, Gramíneas y Enebros. Durante todo el Tardiglaciar se produce una importante progresión de Quercus de hoja caduca, que se instalan en zonas de baja y media latitud, como Andalucia. Durante el Dryas III aumentan el Pino y la estepa mientras retrocede el Quercus. Con el inicio del Holoceno aumentan las temperaturas y precipitaciones. Las estepas se reducen y se desarrolla el bosque (Bernabeu et alii, 1993).

El Holoceno se inicia en 10.300 BP. En latitudes medias y altas se da una mejoría climática, los glaciares sufren una regresión y se eleva el nivel del mar. Las faunas y floras frías desaparecen progresivamente de las latitudes medias. Este tránsito al Holoceno se caracteriza por la recurrencia de procesos erosivos, desarrollados bajo un clima con estaciones marcadas y una pluviometría desigualmente repartida (Aura y Villaverde, 1995).

El Postglaciar se subdivide en varios subperíodos caracterizados por su clima y su vegetación.

El aumento de las temperaturas y de la humedad se detecta desde el interestadio Tardiglaciar. En la región Mediterránea Meridional se muestra como un proceso gradual y ralentizado, menos drástico que en Europa (Aura y Pérez Ripoll, 1995).

\begin{tabular}{|l|l|}
\hline Preboreal (10.300-8.800 BP) & $\begin{array}{l}\text { Progresiva desecación y aumento de la tem- } \\
\text { peratura. }\end{array}$ \\
\hline Boreal (8.800-7.500 BP) & $\begin{array}{l}\text { El aumento de las temperaturas provoca se- } \\
\text { quías y máximo calor continental. } \\
\text { Formaciones estépicas y desarrollo de las cul- } \\
\text { turas epipaleolíticas. }\end{array}$ \\
\hline Atlántico (7.500-4.700 BP) & $\begin{array}{l}\text { Período más cálido y húmedo del Postglaciar } \\
\text { (óptico climático). Neolitización. }\end{array}$ \\
\hline Suboreal (4.700-2.800 BP) & \\
\hline Subatlántico (2.800-hoy) & \\
\hline
\end{tabular}

BREVE HISTORIA DE LA INVESTIGACIÓN

L. Pericot en la década de los 40 y 50 propuso la división del Epipaleolítico en tres fases. 
- Epigravetiense: contemporáneo del Magdaleniense, ocupa la mayor parte de la Península Ibérica.

- Epigraveto-capsiense: industria de geométricos, importada desde el Capsiense norteafricano.

- Neolitización: sobre las industrias geométricas, en el VI Milenio BP.

D. Fletcher Valls en los años 50 acepta el dualismo étnico-cultural y las influencias africanas desde el Gravetiense, estableciendo la siguiente sistematización:

- Mesolítico / Valenciano: predecesor del verdadero Mesolítico y contemporáneo del Magdaleniense de Parpalló, está presente en Mallaetes, Barranc Blanc, Rates Penaes, etc. Equivale al Epigravetiense de Pericot. Los yacimientos costeros se neolitizan sobre esta base, sin cambios industriales; no reciben las influencias geométricas propias de los yacimientos serranos, aunque sí tienen abundante cerámica cardial que reciben vía marítima, pero ésta no llega al interior. Son los autores del primer Arte Levantino.

- Mesolítico II Valenciano: se refiere al Mesolítico pleno, representado en Cocina y Llatas. Se desarrolla en zonas montañosas del interior paralelamente al Mesolítico I, en momentos Postmagdalenienses y Preneolíticos, entre el final del VI Milenio y el final del IV. Sobre esta base industrial se neolitizará el interior, donde no llegaría la cerámica cardial, sino la incisa.

La sistematización de F. Jordá es referencia obligada, ya que es la base sobre la que partirán las investigaciones de J. Fortea. A partir de la elaboración de una tipología para este período, F. Jordá establece la diferenciación del Epipaleolítico por dos industrias:

1. El Epigravetiense microlítico, cuyo fósil director es la hojita de dorso y se divide en tres fases:

- Epigravetiense I: sincrónico en una pequeña parte al SolútreoGravetiense, su etapa más floreciente se desarrollará paralela al Magdaleniense I y II. Supone el renacimiento de las técnicas industriales Gravetienses.

- Epigravetiense la: se caracteriza por la persistencia de la punta de muesca de origen Solutrense tallada con técnica Gravetiense, especialmente en las regiones de Murcia y Almería.

- Epigravetiense lb: caracterizado por la abundancia de hojitas de dorso y por su tendencia al microlitismo. Se observa una fuerte influencia Magdaleniense. 
- Epigravetiense II: Sincrónico del Magdaleniense III y IV, se caracteriza por el aumento de los microrraspadores y hojitas de dorso.

- Epigravetiense III: Sincrónico al Magdaleniense V y VI e inicios del Mesolítico o enraíza con el Neolítico. Continúan las hojitas de dorso, algunas son microgravettes. Lo divide en dos facies:

- Facies Levantina: representa una continuidad de los elementos anteriores (indígenas)

- Facies Capsiense: se introducen elemeritos geométricos de origen Capsiense y enlaza con la siguiente fase.

2. El Mesolítico geométrico, dividido también en tres fases:

- Mesolítico I: representado en el nivel inferior de la Cueva de la Cocina (Dos Aguas, Valencia).

- Mesolítico II: representado en el nivel medio del mismo yacimiento.

- Mesolítico III: localizado en el nivel superior, dará paso al Neolítico desde un medio puramente Mesolítico.

3. El Neolítico, del que supone dos facies contemporáneas, integradas por dos etnias diferentes:

- Neolítico Costero: con cerámica cardial y pocos geométricos.

- Neolítico Interior: sin cerámica cardial y con abundantes geométricos.

La Tesis de J. Fortea supone una serie de rupturas con el esquema anterior: el Epigravetiense, ahora llamado Epipaleolítico Microlaminar, ya no es contemporáneo del Magdaleniense, sino sucesivo y además derivado de él; las tesis africanistas son abandonadas definitivamente; demuestra que el substrato geométrico persiste hasta el Eneolítico en varias zonas; fija una cronología absoluta y compara las industrias con otras semejantes; y, por último, se acepta la unidad cultural del Epipaleolítico en todo el Mediterráneo Español.

Elabora una lista-tipo con la que analiza todos los yacimientos entonces conocidos y compara las estratigrafías con el fin de fijar su cronología (figura 3). Todo esto le lleva a diferenciar dos complejos industriales subdivididos a su vez en varias facies definidas por unas características propias, resultando el esquema que a continuación exponemos:

- Complejo Microlaminar: compliesto por dos facies y un tercer grupo, se desarrolla a partir del Magdaleniense y muy influenciado por éste, negando la sincronicidad propuesta por investigadores anteriores. Las dos facies, Mallaetes y Sant Gregori, corresponden a distintas facetas de una evolución industrial similar. Se desarrollan sincrónicamente, desde el XII 


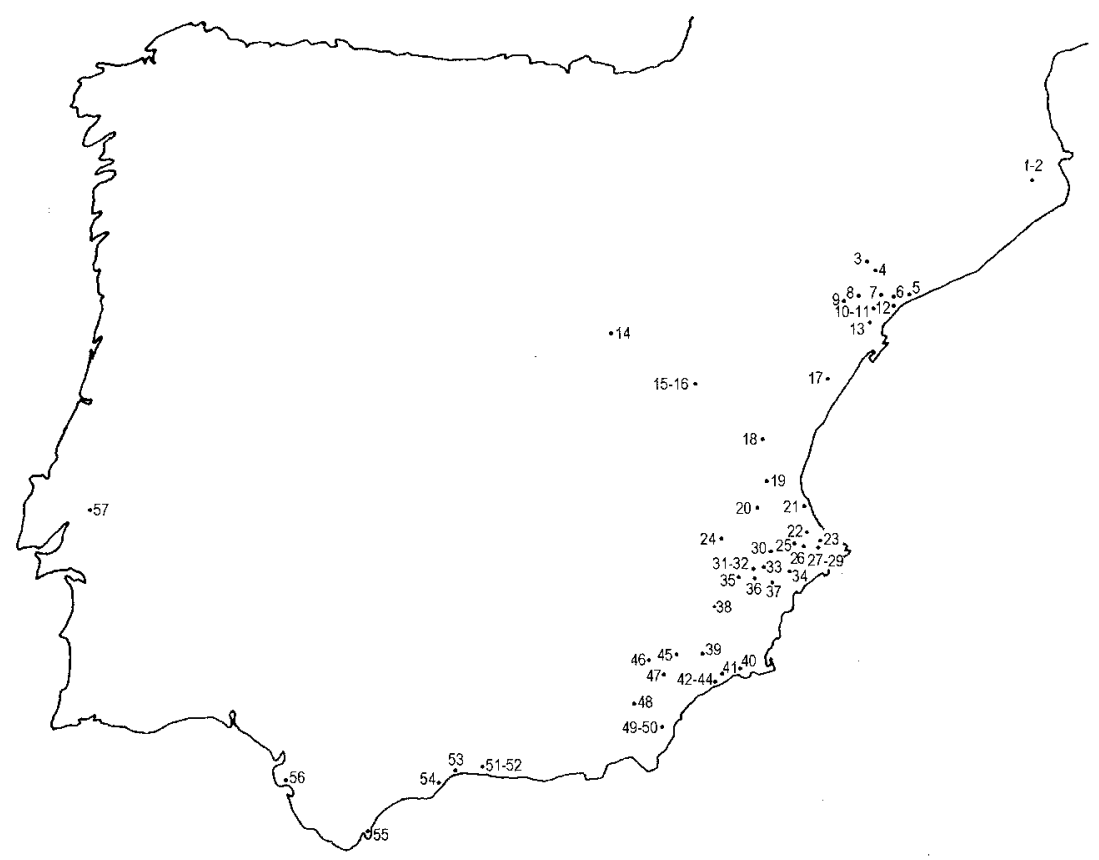

Figura 3. Yacimieritos tratados en la Tesis de J. Fortea (1973): Los Complejos Microlaminares y Geométricos del Epipaleolítico Mediterráneo Español:
1. Reclau Viver
2. Bora Gran
3. Cogul
4. Filador
5. Camping de Salou
6. Patou
7. Sant Gregori
8. Sol de la Piñera
9. Serdá
10. Morral de Perpinyá
11. Moll de la Bleda
12. L'Areny
13. Mallada
14. Aguilar de Anguita-Alcolea del Pinar
15. Cocinilla del Obispo
16. Doña Clotilde
17. Yacimientos de Valltorta
18. Llatas
19. Truche

20. Cocina
21. Volcán del Faro
22. Parpalló
23. Mallaetes
24. Cueva Negra de Alpera
25. Or
26. Maravelles
27. Rates Penaes
28. Barranc Blanc
29. Empardo
30. Sarsa
31. Casa de Lara
32. Arenal de la Virgen
33. Cueva Pequeña de la
34. Huesa Tacaña
35. Pinar de Tarruella
36. Lagrimal
37. Cueva Grande de la Huesa
Tacaña

Milenio hasta bien entrado el VIII BP; climáticamente correspondería a Alleröd, Dryas III y gran parte del Preboreal.

1. Facies Sant Gregori: Presenta una estructura más aziliense debido a su mayor proximidad a Francia. Caracterizada por la abundancia de raspadores, principalmente sobre lasca y de dimensiones casi macrolíticas, y 
un índice de buril prácticamente inexistente, igual que el de perforadores y el de útiles compuestos. Las hojitas de dorso, así como las muescas y denticulados, cuentan con una buena representación y los geométricos están presentes, aunque en pequeño número.

Fase A: Representada en Sant Gregori, nivel 1 y 2.

Fase B: Representada en Sant Gregori 3-4 y 5, L'Areny y Pinar de Tarruella.

Fase C: Únicamente presente en el estrato Vl (según Vilaseca) de Filador (estratos 8 y 9 del SERP) (García Argüelles et alii, 1992)

2. Facies Mallaetes: Desarrollada desde el final del Magdaleniense hasta el Neolítico Antiguo, se caracteriza por un menor índice de raspadores y mayor de buriles que en la facies anterior, aunque siempre favorable a los primeros, así como por la fuerte presencia de hojitas de dorso, siendo los tipos fundamentales los raspadores y hojitas y, en menor grado, el buril. La estructura tipológica es similar a la de Sant Gregori, pero el estilo industrial y las estadísticas son muy distintos. La afirmación de que este tipo de industria persista hasta la aparición de la cerámica cardial quizá constituya el punto con el que mostramos un mayor desacuerdo con el autor.

Fase A: La supone en las capas «epigravetienses» del Volcán del Faro, situadas entre los niveles de triángulos escalenos (Magdalenienses) y los niveles cerámicos, aún sin estudiar cuando se escribió esta obra. Definirían el principio de esta facies.

Fase $B$ : Caracterizada en las capas acerámicas de Mallaetes.

Fase $C$ : Representada en las capas con fragmentos de cerámica cardial de Mallaetes.

3. Tercer complejo industrial: compuesto por una serie de industrias en las que se observa un buen desarrollo microlaminar, con hojitas de dorso y triángulos escalenos alargados y buena representación de los buriles. Se caracteriza, en general, por su filiación Magdaleniense. Nosotros consideramos estas industrias puramente Magdalenienses o, incluso, más antiguas o muy difíciles de precisar.

- Complejo Geométrico: reconoce dentro de éste dos complejos industriales que se continúan en el tiempo, diferenciados según sea su elemento caracterizador el trapecio o el triángulo: las industrias del tipo de Filador tienen una base triangular (Sauveterroide), mientras que las del tipo Cocina tienen una base trapezoidal (Tardenoide o Sauveterroide final con trapecios).

1. Facies Filador o Sauveterroide: se desarrolla entre el final del $X$ y todo el IX Milenio BP, abarcando buena parte del Preboreal y otra del Boreal. Se caracteriza por el equilibrio tipológico existente entre raspadores, hojitas de dorso, muescas y denticulados y microlitos geométricos. Estos últimos, 
fundamentalmente triángulos y algunos segmentos, nunca trapecios, se caracterizan por su pequeño tamaño, siendo descritos como «pigmeos». Como contraste, un utillaje macrolítico, nucleiforme y denticulado invadirá la industria a la vez que desaparecen las hojitas y los geométricos, creando un complejo industrial radicalmente distinto que pone el punto final a esta facies. Se encuentra representada en los niveles $V$ y $V I$ o estratos 7 y 8 de Filador.

2. Facies Cocina o Tardenoide: ocupa el final del VIII y primera mitad del VII Milenio, durante el Boreal y el Atlántico, para desaparecer en el Subboreal. Se divide en cuatro horizontes industriales definidos por los niveles del yacimiento homónimo, acerámicos los dos primeros y con cerámica los dos últimos.

Fase A-Cocina l: Representada en Cocina I y en la Cueva Pequeña de la Huesa Tacaña. Muescas y denticulados junto con geométricos componen más del $70 \%$ de la industria. Se desarrolla en torno al VIII Milenio, durante el paso del Boreal al Atlántico.

Fase B-Cocina II: Representada por Cocina II y Sol de la Piñera. Los triángulos con ápice triédrico o espina central tipo Cocina, derivados de la forma industrial trapezoidal, son el útil más característico de este momento.

Fase C-Cocina III: Aparece cerámica cardial junto con semicírculos, segmentos y hojitas tipo Cocina (apuntadas y con espina central). Se inicia con la llegada del Neolítico Cardial al País Valenciano, en torno a 6.500 B.P.

Fase $D$-Cocina $N$ : Aparece cerámica peinada y se generaliza la técnica de retoque a doble bisel en los segmentos y medias lunas.

\section{ÚLTIMAS INVESTIGACIONES SOBRE EL FINAL DEL PALEOLITIICO Y EL EPIPALEOLITICO}

El Magdaleniense Mediterráneo tiene en realidad una vida bastante corta en cuanto a su estudio. Para la investigación tradicional no tenía un gran significado, ya que al contrario que su homónimo de la Región FrancoCantábrica-Pirenaica, dotado de una gran personalidad, el del Levante Mediterráneo Ibérico se veía obligado a compartir escenario y cronología con el Epigravetiense, superpuesto al Solutreo-Gravetiense. Sin embargo a partir de los trabajos de J. Fortea (1973) y de otras investigaciones el Magdaleniense Mediterráneo cobró importancia y pasó a ocupar un primer plano en la investigación, dando como resultado el reconocimiento de un complejo industrial y cronocultural con características propias y relevantes, objetivo de numerosas investigaciones mediante las cuales se ha llegado a conformar una secuencia precisa y que, en el trabajo que nos ocupa, se muestra fundamental para llegar a conocer el proceso del final del Paleolítico en la Península Ibérica. En efecto, no podemos obviar este momento si pre- 
tendemos hablar del Epipaleolítico, ya que supone no sólo el antecedente sino también la base sobre la que se desarrollarán todos los aspectos del período. Incluso, como más adelante discutiremos, es posible que no podamos diferenciar Magdaleniense Superior Final y Epipaleolítico como realidades culturales distintas.

El Magdaleniense Superior aparece ampliamente distribuido a lo largo de toda la costa Mediterránea. Cronológicamente se desarrolla durante el Interestadio Tardiglaciar (14.000-10.500 BP). A partir del 14.000 se generaliza la talla laminar y el utillaje microlaminar alcanza un peso específico en la mayoría de las series. La industria ósea cuenta con un reducido pero significativo número de tipos: arpones, puntas de diversa morfología, variIlas, agujas y anzuelos rectos. Las secciones suelen ser angulosas, especialmente cuadradas (Aura y Villaverde, 1995).

Los momentos articulados en torno al XIII Milenio BP son los que presentan un mayor número de dataciones y la máxima variabilidad tipológica, no siempre coincidente con las características propia del Magdaleniense Superior Mediterráneo, sino que en muchos casos son más parecidas a las descritas por Fortea para su Complejo Epipaleolítico Microlaminar. En este grupo quedan incluidos Chaves, Matutano, Verdelpino, Tossal de la Roca y Nerja. Los momentos finales quedan inscritos entre 11.000 y 10.500 $\mathrm{BP}$, momento en que se reconoce una mayor homogeneidad en cuanto a la producción industrial. La fecha de inicio del Epipaleolítico Microlaminar Mediterráneo ha sido fijada en Mallaetes VII (10.370 \pm 150 B.P.) (Fortea, 1973), poniendo punto final al Magdaleniense Superior Mediterráneo. Sin embargo es complejo separar ambos momentos, ya que lo que encontramos en este período es una continuidad industrial, tal vez matizada por pequeñas variaciones porcentuales, y un más que sospechoso solapamiento en las dataciones (Aura, 1992). La lenta evolución industrial de los yacimientos dificulta, a su vez, la diferenciación de distintos complejos industriales.

Han sido varios los investigadores que han intentado establecer una secuencia para el Magdaleniense Superior Mediterráneo, encontrando todos ellos un problema difícil de solucionar: la enorme variabilidad que presenta la industria lítica.

Una de las sistematizaciones más importantes del Magdaleniense Mediterráneo ha sido la realizada por Valentín Villaverde (1984), que puede resumirse de la siguiente forma:

- Magdaleniense Inferior: se correspondería con el Magdaleniense I y II clásico. Industrialmente se caracteriza por un predominio de los raspadores sobre los buriles, pocas hojitas de dorso y gran cantidad de piezas con retoque continuo. Se encuentran azagayas cortas con decoración lineal o en espiga. 
- Magdaleniense Medio: se correspondería con el Magdaleniense Medio Francés (III y IV). Los buriles y el utillaje microlítico aumentan, mientras que se hacen más escasas las piezas con retoque continuo. Aparecen triángulos, azagayas con doble bisel, varillas plano-convexas y protoarpones.

- Magdaleniense Superior: el índice de buril es superior al de los raspadores. Entre los primeros dominan los diedros sobre los otros tipos; las hojitas de dorso abundan y los triángulos escalenos ceden su lugar a las hojitas truncadas. En cuanto a la industria ósea, aparecen los arpones.

A partir del estudio del Magdaleniense de la Cueva de Parpalló (Gandía, Valencia), su investigador propone una estructuración de este período, dividido en dos grandes unidades: el Magdaleniense Antiguo o Badegouliense tipo Parpalló y el Magdaleniense Superior (Aura, 1988).

En líneas generales, el Magdaleniense Antiguo supone un cambio rotundo tanto en lo técnico como en lo tipológico con respecto al Solutrense Evolucionado que lo precede. A lo largo del XVII Milenio la Punta de Muesca Mediterránea, característica del período anterior, será sustituida por otro tipo de proyectil, de asta, de dimensiones cortas, sección redondeada y base frecuentemente biselada (Aura y Villaverde, 1995). En el aspecto tipológico se caracteriza por el espectacular descenso del utillaje microlaminar y del grupo de los buriles, así como por el aumento de las piezas con retoques continuos, raederas y denticulados. La industria adquiere un aspecto arcaico, dominada por grupos tipológicos básicos y retoque simple. Cronológicamente resulta muy tardío respecto a la región clásica francesa, pero coincide con el inicio del Magdaleniense Inferior y Badegouliense de la región Cantábrica y del Sureste Francés. Se distinguen en el Magdaleniense Antiguo Mediterráneo dos horizontes, el A, caracterizado por un importante porcentaje de raspadores cortos y espesos y un bajo índice microlaminar y de buriles, y el $\mathrm{B}$, con menor número de raspadores y buriles y mayor protagonismo de piezas retocadas, muescas-denticulados y raederas (Aura, 1988; Villaverde, 1992).

El Magdaleniense Superior, a partir del $14.000 \mathrm{BP}$, se define por la asociación de arpones, puntas de bisel simple y doble de sección angulosa, relación buril-raspador equilibrada o favorable al primero e incremento de la técnica microlaminar. El grupo del utillaje microlaminar alcanza un peso específico en la mayoría de las series y muestra una notable variedad, registrándose geométricos (triángulos), hojitas o puntas truncadas, hojitas o puntas de dorso y truncatura y hojitas o puntas de dorso y denticulación (Aura, 1992). La industria ósea muestra un reducido pero significativo número de tipos: arpones, puntas de diversa morfología, varillas, agujas y anzuelos rectos. Las secciones adquieren en esta ocasión formas más angulosas, 
especialmente tendentes a las cuadradas. Este momento cronocultural aparece ampliamente distribuido a lo largo de toda la costa Mediterránea, desde Gerona hasta Málaga y con penetraciones en el interior (Cacho, 1989), representado en gran cantidad de yacimientos, entre los que destacan Matutano, Parpalló, Cendres, Tossal de la Roca, Mejillones, Caballo, Algarrobo, Hoyo de la Mina y Nerja. Se intuyen tres horizontes: Magdaleniense Superior A o Inicial, Magdaleniense Superior B o Pleno y Magdaleniense Superior C (Aura, 1988; 1995).

El primer tipo (A) se desarrolla durante el XIV Milenio BP. Su rasgo más significativo en cuanto a industria lítica es el conjunto de triángulos y hojitas truncadas y la diversificación del utillaje microlaminar; en cuanto a la industria ósea cabe destacar las azagayas con bisel doble o simple de sección cuadrangular o angulosa, las varillas y algunas agujas. Se identifica en Parpalló-Talud capa 4 y en la base de Matutano IV (Aura, 1995).

El tipo B o Pleno, desarrollado durante XIII y XII Milenios BP, puede caracterizarse genéricamente como Magdaleniense con triángulos y arpones. La relación raspador-buril se muestra equilibrada o favorable al segundo tipo; el utillaje microlaminar se muestra muy diversificado y cuenta con la presencia de triángulos-hojitas escalenas. En cuanto a la industria ósea se repiten los morfotipos anteriores, incorporándose ahora arpones y anzuelos rectos (Aura, 1995).

El tipo $C$, que se desarrolla durante la primera mitad del XI Milenio, se considera de transición hacia el Epipaleolítico (Aura, 1995). Existe un mayor equilibrio entre raspadores y buriles, el utillaje microlaminar es más estereotipado y el utillaje óseo muestra una importante reducción (Aura y Villaverde, 1995). En los conjuntos que no contienen arpones -teóricamente más evolucionados (Aura, 1992)- el utillaje microlaminar presenta una variedad mucho menor y el grupo de los buriles pierde entidad en favor de los raspadores y el utillaje de sustrato. Estos rasgos irán perfilando los momentos inmediatamente posteriores (Epipaleolítico Antiguo) a partir del fin del Tardiglaciar. Niveles considerados de transición al Epipaleolítico, como es el caso de Matutano IIB y Tossal I-int. muestran, efectivamente, esta secuencia industrial: se caracterizan por el marcado dominio del índice de raspador sobre el de buril, una buena representación de las hojitas de dorso (no en el caso de Matutano) y una importante presencia de muescas y denticulados. Todos estos aspectos coinciden con la definición del Epipaleolítico Microlaminar de Fortea; sin embargo la cuestión cronológica es absolutamente contradictoria. En el caso del Tossal, las dataciones radiocarbónicas han dado como resultado que el nivel II (Magdaleniense Final) se desarrolla durante Dryas II, y el nivel I (transición 
al Epipaleolítico) durante Alleröd, mientras que si tuviéramos que situar estas industrias a partir de la clasificación de Fortea, no podríamos suponer de ningún modo un momento anterior a Dryas III.

Hasta hace poco tiempo se ha venido considerando que las colecciones de aspecto Magdaleniense que contiene arpones son, en efecto, Magdalenienses, mientras que si no presentan dicho útil se clasifican dentro del Epipaleolítico. Sin embargo seguimos hablando de la misma industria lítica, los mismos hábitats, el mismo modo de obtención de recursos y la misma cronología. La ausencia o presencia de un determinado útil no puede darnos una atribución cultural; su existencia puede depender de infinitos factores, como la disponibilidad de la materia prima o la necesidad de que tal útil sea fabricado, máxime si estamos hablando de útiles reales, diseñados para la explotación del medio, no elementos votivos o de significación social. Por ello nos inclinamos hacia la división del Magdaleniense Superior Final en dos grupos contemporáneos a partir de la existencia o no del tipo de útil citado: el Magdaleniense con arpones y el Magdaleniense sin arpones (Cacho, 1989).

El Magdaleniense con arpones, aun dentro de una enorme variabilidad, presenta una industria caracterizada por una fuerte presencia de microlitos (hojitas) y el dominio de buriles sobre raspadores. Los arpones suelen tener una sola fila de dientes y aparecen acompañados por otros tipos, como azagayas, varillas y agujas. Dentro de este conjunto podemos incluir Parpalló, La Bora Gran, la Cueva de les Cendres, Matutano III, la Cueva de los Mejillones, la del Higuerón, el Rincón de la Victoria y la Cueva de Nerja.

El Magdaleniense sin arpones presenta otro tipo de útiles en cuanto a su industria ósea, como azagayas, agujas y punzones. La industria lítica muestra cierta heterogeneidad: los buriles suelen ser más numerosos que los raspadores, aunque no siempre; los porcentajes de hojitas suelen ser altos, aunque presentan muchas variaciones en función de sus distintas fases evolutivas o de la adaptación a distintos medios ecológicos. Dentro de este conjunto se incluyen los yacimientos de la Cova del Parco, Tossal de la Roca, Hoyo de la Mina y Volcán del Faro.

La continuidad entre Magdaleniense Superior y Epipaleolítico Inicial es evidente. Sólo a partir del X Milenio BP se manifiestan probablemente los rasgos característicos del Epipaleolítico: alto índice de raspador, caída del índice de buril, frecuencias moderadas de índice de hojitas (menor a $20 \%$ ) y desigual enriquecimiento de truncaturas, muescas-denticulados y piezas retocadas. El arte mueble y las producciones óseas se pierden casi por completo. Sin embargo la enorme variabilidad interna provoca que en no pocas ocasiones no se cumplan estas características. Existe la posibilidad de que estemos hablando de un mismo complejo industrial (Aura y Pérez Ripoll, 1992). 
En líneas generales se observa que a partir del Magdaleniense Superior se ocupan nuevos sitios, hasta entonces deshabitados (Aura et alii, 1993). Los cambios en el nivel del mar y en la línea de costa han podido ocultar un gran número de yacimientos ubicados sobre la plataforma. Son escasos también los datos sobre yacimientos al aire libre por las propias dificultades de conservación que conllevan. La mayoría de los yacimientos se distribuyen por una franja costera de $50 \mathrm{Km}$ de anchura que muestra una importante diversidad ecológica, topográfica y bioclimática dentro de una superficie reducida. Parece que los yacimientos situados a mayor altura y con menos condiciones de habitabilidad fueron ocupados durante las épocas estivales (Aura y Pérez Ripoll, 1992). También parece desprenderse del patrón de asentamientos una preferencia por ocupar zonas de contacto entre distintos ecosistemas, como el piedemonte de las llanuras litorales o el contacto con relieves escarpados, dominando amplios valles, sobre límites topográficos y ecológicos que permitan la utilización de diversos tipos de recursos (Aura y Pérez Ripoll, 1992).

En la transición del Paleolítico Superior Final al Epipaleolítico se observa, además de una mayor especialización en el aprovechamiento de recursos alimentarios, una mayor diversificación de los mismos, incorporando recursos de menor tamaño, como aves, peces, moluscos y vegetales. Las variaciones en la utilización de los recursos dan lugar a una serie de diferencias en los sistemas de asentamiento: durante el Tardiglaciar y el Holoceno la implantación sobre el territorio se hace de manera más vertebrada, con campamentos de duración y funcionalidad diversas, según los entornos de explotación en que se ubican (Aura et alii, 1993).

\begin{tabular}{|l|c|c|c|}
\hline YACIMIENTO & MSM & E. Genérico & EGM \\
\hline Matutano & & & \\
\hline Volcán del Faro & & & \\
\hline Tossal de la Roca & & & \\
\hline Cendres & & & \\
\hline Fosca (Alicante) & & & \\
\hline Molino Vadico & & \\
\hline Cueva del Algarrobo & & \\
\hline Cova del Parco & & & \\
\hline Abauntz & & \\
\hline Chaves & & \\
\hline Forcas I & & \\
\hline Nerja & & & \\
\hline
\end{tabular}

Figura 4. Continuidad en ocupación o nueva implantación de yacimientos entre el Paleolítico Superior Final y el Epipaleolítico. 
La industria del Epipaleolítico Inicial muestra una talla técnicamente laminar en los soportes empleados para la obtención de proyectiles, mientras que para el resto de los grupos (raspadores, buriles, perforadores, truncaturas, muescas-denticulados y piezas retocadas) se intuyen desiguales porcentajes de hojas y lascas. Las piezas sufren un proceso de microlitización respecto al Magdaleniense Superior. La presencia de macroútiles (machacadores, percutores, cantos tallados) es mayor cuanto más nos adentramos en el Holoceno (Aura y Pérez Ripoll, 1995).

Fortea demostró la derivación del Magdaleniense de los primeros momentos Epipaleolíticos: ésto es comprobable en aquellos niveles caracterizados por la presencia de triángulos escalenos, buriles y arpones infrapuestos a otros con industrias microlaminares. El proceso evolutivo de la industria lítica se define por el aumento de los raspadores, la disminución de los buriles y la relativa importancia de las hojitas de dorso, así como por la paulatina desaparición de la industria ósea y del arte. Pero incluso dentro de estas vagas características definidas, la variabilidad es tal que resulta imposible articular el momento correspondiente al final del Magdaleniense y el principio del Epipaleolítico, especialmente debido a la gran amplitud temporal del Epipaleolítico Inicial Mediterráneo y a que no existe ningún elemento definitorio que lo diferencie del Magdaleniense Superior Final (Domenech, 1990).

En el Epipaleolítico catalán parecen coexistir dos grupos de asentamientos Epipaleolíticos diferenciados (García Argüelles et alii, 1992): un primer grupo entronca directamente con la tradición Paleolítica Mediterránea. Dentro de este grupo se distinguen dos momentos iniciales: uno más antiguo, caracterizado en los yacimientos de la Font Voltada, la capa 8 de la Balma Margineda y los niveles inferiores de la Cova de la Guineu, suele presentar fuertes porcentajes de raspadores, hojas de dorso, puntas de dorso curvo y algunos buriles; otro posterior representado en el estrato 1c de Sant Gregori, en el nivel Illb de la Cova de la Guineu y en el Abrigo de L'Areny, donde comienzan a aparecer algunos microburiles (García Argüelles et alii, 1992).

El enlace entre esta primera fase y la geométrica queda representado en la Balma de Gai, donde junto a numerosos raspadores y elementos de dorso aparece un débil índice de geometrización (García Argüelles et alii, 1992). La facies geométrica plena se caracteriza industrialmente por una importante presencia de geométricos y de la técnica de microburil. Durante el Epipaleolítico en proceso de transformación económica aparecen los trapecios y desaparece la técnica de microburil (García Argüelles et alii, 1992). 
El segundo grupo del Epipaleolítico Catalán queda restringido al sector noroeste de la región. Los asentamientos se caracterizan por apartarse de la secuencia descrita. Su principal nexo de unión es la utilización de materias primas locales, como el cuarzo, la cuarcita y la caliza, y su tipología, dominada por el retoque simple (denticulados, piezas con retoque continuo y raspadores). Estos yacimientos son la Font del Ros, el Cingle Vermell y la Sota Palou. Sus cronologías son equiparables a las del grupo anterior, pero las técnicas de talla varían como consecuencia de la utilización de una materia prima distinta (García Argüelles et alii, 1992).

Pocos yacimientos registran la sucesión entre el Epipaleolítico Inicial y el Epipaleolítico Geométrico. Desde el punto de vista tipológico existen grandes diferencias, sobre todo en forma, tamaño y técnica de fabricación de los proyectiles (Aura y Pérez Ripoll, 1995).

\begin{tabular}{|l|l|l|l|}
\hline YACIMIENTO & E. inicial & E. Geométrico & E. Final (no G) \\
\hline E. Inicial & & & \\
\hline E. Geométrico & & & \\
\hline E. Final (no G) & & & \\
\hline Santa Maira & & & \\
\hline El Filador & & & \\
\hline Forcas II & & & \\
\hline Montico de Charratu & & & \\
\hline Berroberría & & & \\
\hline Zatoya & & & \\
\hline Forcas l & & & \\
\hline
\end{tabular}

Figura 5. Continuidad en ocupación o nueva implantación de yacimientos entre el Epipaleolítico Inicial y el Final, presente o no industria geométrica.

Algunas series relacionadas con el Sauveterriense incorporan sobre una estructura básicamente propia del Epipaleolítico Inicial algunos triángulos y segmentos. Este estilo aparece en Cataluña con posterioridad al 10.000 BP, pero no ha sido identificado al sur del Ebro. En este área el sustrato del Epipaleolítico Genérico sólo será desarticulado con el geometrismo trapezoidal de la facies Cocina (Aura y Pérez Ripoll, 1995).

Desde finales del Tardiglaciar se observa cómo las áreas litorales van creciendo en importancia, siendo objeto de ocupaciones cada vez más largas, que implican una mayor inversión de trabajo y desarrollo de las técnicas de almacenamiento, con una consecuente pérdida de la movilidad residencial y un aumento de la movilidad logística (Aura y Pérez Ripoll, 1995). 
Las industrias Epipaleolíticas de la facies Cocina preceden directamente a los primeros influjos neolíticos, asisten a su desarrollo y perviven durante fases más o menos avanzadas del mismo. Desde la publicación de la Tesis de Fortea, el conocimiento de este momento ha sido ampliado por la investigación de nuevos yacimientos, como Costalena y Botiquería en el Valle del Ebro. Los yacimientos del mismo momento ubicados en el Alto Aragón o Navarra parecen tener más relación con el sur de Francia que con la vertiente Mediterránea Española. En Cataluña son bastante escasos los yacimientos relacionables con la facies Cocina. En el País Valenciano destacan los hallazgos de Can Ballester y el Estany Gran, y en Andalucía Oriental Valdecuevas y Nacimiento (Juan Cabanilles, 1985).

\begin{tabular}{|l|c|c|}
\hline YACIMIENTO & Epipaleolítico Final & Neolítico \\
\hline Nerja & No G. & \\
\hline Forcas I & No G. & \\
\hline Berroberría & G. & \\
\hline Zatoya & G. & \\
\hline Botiquería & G. & \\
\hline Costalena & G. & \\
\hline Padre Areso & G. & \\
\hline Forcas II & G. & \\
\hline Montico de Charratu & G. & \\
\hline Cova del Parco & G. & \\
\hline El Filador & G. & \\
\hline Nacimiento & G. \\
\hline Fosca & No G. \\
\hline Font del Ros & Mesolítico & \\
\hline Cova de la Guineu & G. \\
\hline Abric de la Falguera & G. \\
\hline Lagrimal & No G. \\
\hline Santa Maira & No G. \\
\hline
\end{tabular}

Figura 6. Continuidad en ocupación o nueva implantación de yacimientos entre el Epipaleolítico Final y el Neolítico.

Debido a que el Epipaleolítico del Valle del Ebro presenta unas características ligeramente distintas a las de la costa Mediterránea y a que ha sido objeto de síntesis más recientes, lo trataremos aparte de aquellas otras áreas. 
Se distinguen tres entornos geográficos en el Valle del Ebro (Cava, 1994).

1) Bajo Aragón. Comprende la cuenca media del Matarraña y su afluente el Algás, que desagua en el Ebro por la derecha. La zona queda circunscrita entre Teruel, Zaragoza y Tarragona. La costa Mediterránea se encuentra a unos 60 ó $65 \mathrm{Km}$. La zona es una depresión de alturas inferiores a $400 \mathrm{~m}$, limitada al sur y al este por el Sistema Costero-Catalán. El clima actual se caracteriza por unas condiciones semiáridas, con un paisaje de área mediterránea subárida: bosque de pino y encinar en las zonas altas y paisaje de matorral en las zonas más estepizadas. En esta zona se encuentran: Botiquería dels Moros, Els Secans (Mazaleón, Teruel); El Pontet, Costalena, Abrigo Ahumado (Maella, Zaragoza); Abrigo del Ángel (Ladruñán, Teruel); Sol de la Piñera y El Serdá (Fabara, Zaragoza). Entran dentro de la tradición Geométrica del Mediterráneo. Las secuencias líticas de estos yacimientos son un buen modelo de evolución in situ del geometrismo desde mediados del VIII Milenio a mediados del VII BP. El proceso de neolítización es de influencia mediterránea, con cerámicas impresas.

2) Vertiente Sur del Pirineo. La ocupación humana se realiza durante el Würm Reciente y la primera mitad del Holoceno. Los yacimientos de esta zona son: Balma Margineda (Andorra); Forcas (Graus, Huesca); Padre Areso (Bigüezal, Navarra); Aizpea (Arive, Navarra); Zatoya (Abaurrea Alta, Navarra); Abauntz (Arraiz, Navarra). Se trata de asentamientos en espacios pirenaicos o prepirenaicos, en alturas entre 600 y $1.000 \mathrm{~m}$ sobre el nivel del mar. Los entornos de estos yacimientos presentan una gran variedad de ecosistemas: abiertos, llanos, bosques y roquedos.

3) Alta Cuenca del Ebro. Es una prolongación de la zona anterior. Abarca parte de Álava y las zonas colindantes de la Navarra media, atravesadas de oeste a este por una serie paralela de alturas montañosas que componen las estribaciones más meridionales del Pirineo Occidental. Los yacimientos de Montico de Charratu (Albaina, Álava) y Berniollo (Subijana, Álava) muestran un industria de hojas y hojitas de dorso que representan las últimas manifestaciones culturales del Tardiglaciar y el Preboreal. Otros yacimientos inscritos en esta zona son el Abrigo de la Peña (Marañón, Navarra) y Fuente Hoz (Anúcita, Álava).

Las secuencias de estas dos últimas zonas guardan más relación con la región Franco-Cantábrica que con la Mediterránea.

No se ha encontrado en el Valle del Ebro ningún yacimiento Epipaleolítico de tipo Microlaminar, ya que los que por posición corresponden a esta secuencia son pobres en hojitas. Se trata de momentos postazilienses. En la base de las secuencia del Epipaleolítico Geométrico existen niveles de 
Epipaleolítico Macrolítico, en cuyos conjuntos destacan las piezas denticuladas (Utrilla y Mazo, 1994).

La secuencia Aragonesa repite aquello que es común en la mayoría de los yacimientos de la región Mediterránea: una discontinuidad deposicional entre los niveles con industrias posteriores al Solutrense y los que se superponen (Aura y Villaverde, 1995).

Se establece de la siguiente manera el esquema básico para la evolución del Epipaleolítico/Mesolítico del Valle del Ebro (Barandiarán y Cava, 1985):

I. - Aziliense típico (Berroberría-d, base)

- Epipaleolítico Inicial, Epimagdaleniense o Epiaziloide (Zatoya II, Abauntz d)

II. - Microlaminar o Epipaleolítico Genérico (Berroberría-d techo, Zatoya lb, niveles inferiores del Montico)

- Epipaleolítico de facies Geométrica (Costalena c3, Botiquería 2 y 4, Berroberría c, La Peña d)

III. - Epipaleolítico Geométrico con cerámica/Neolítico (Zatoya I, Costalena c2 y c1, Botiquería 6 y 8

Desde el punto de vista cronológico y de evolución de las industrias se establecen 4 momentos consecutivos reconocibles (Cava, 1994):

\section{Primeras manifestaciones industriales del Holoceno}

La ocupación del Valle del Ebro durante el Paleolítico Superior es bastante escasa. Las condiciones extremas del clima Würmiense hacen a la zona poco propicia para la habitación humana. Las ocupaciones suelen ser estacionales. Con la transición al Holoceno y la consecuente mejoría climática los grupos humanos accedieron desde las áreas circundantes. La documentación anterior al VIII Milenio BP es escasa. En varios yacimientos se encuentran niveles inmediatamente anteriores a la irrupción del geometrismo. En la Balma Margineda la ocupación se remonta a un Paleolítico Superior Final o a un Epipaleolítico Antiguo de tendencia Aziloide (niveles 10 a 7). En el nivel 6 (Preboreal) irrumpen los geométricos (triángulos y segmentos fabricados con la técnica del microburil), sobre una base Aziloide con fechas comprendidas entre el XI y X Milenios BP. La industria Mesolítica puede relacionarse con ciertas facies Sauveterroides. Es el único yacimiento de la zona que presenta unos caracteres Sauveterrienses con anterioridad al VIII Milenio BP: las influencias llegan antes a este yacimiento porque por su situación geográfica tiene mayor contacto con el área francesa. 
El Magdaleniense Final y transición al Aziliense de Zatoya (nivel lb) se fechan en la segunda mitad del IX Milenio BP, dentro del Boreal. Se trata de una ocupación poco densa y estacional protagonizada por grupos que conservan una tradición industrial Paleolítica. La industria lítica está dominada por piezas de dorso y denticulados y presenta similitudes con el Paleolítico Final. La presencia de algunos elementos ultramicrolíticos denuncia una relación lejana con un estadio Geométrico de matriz Sauveterriense (Cava, 1994).

En varios yacimientos de Epipaleolítico pleno se han localizado infrapuestos a los niveles geométricos ocupaciones con industrias compuestas por piezas no microlíticas en soportes cortos (lascas) y a veces espesos, con amplias denticulaciones por percusión y de talla tosca, como es el caso del nivel d de Forcas II o los niveles 13 y 8 del Abrigo del Ángel, que son sincrónicos o inmediatamente anteriores a Zatoya lb. Han sido descritos niveles similares también en Costalena-d base y en El Pontet, niveles i y g (Cava, 1994).

\section{Geometrización del Epipaleolítico Pleno}

A partir de finales del IX y principios del VII Milenio BP comienzan a formarse en la Cuenca del Ebro la mayoría de los niveles con industrias Geométricas. La máxima representación corresponde a los tipos trapezoidales, con menos triángulos, a menudo con lados cóncavos y casi siempre con retoque abrupto. La técnica del microburil se utiliza ampliamente para la elaboración de geométricos. Se encuentran porcentajes variables pero representativos de raspadores, denticulados y, en menor medida, buriles, perforadores, etc. La industria ósea suele estar mal representada. Los inicios de esta tendencia industrial se dilatan y varían según el área geográfica, siendo más antiguas las fechas de la mitad occidental en casi medio milenio que las de los yacimientos situados en la mitad oriental (Cava, 1994).

\section{Evolución final del Epipaleolítico}

Los trapecios van siendo sustituidos paulatinamente por los triángulos. Se sigue utilizando la técnica del microburil, sigue dominando el retoque abrupto y el utillaje de sustrato tiene las mismas características que en el momento anterior. Se da un importante aumento de las hojitas de dorso, de tipos en general apuntados y en menor proporción truncados. Según las distintas áreas geográficas se dan distintos modelos tipológicos, debido a diferentes influencias: así, en la mitad oriental se sigue un modelo evolutivo 
similar al del Mediterráneo, dominado por la secuencia de la Cueva de la Cocina, apareciendo triángulos con ápice triédrico. En la mitad occidental, sobre todo en los yacimientos próximos al Pirineo, aparecen tipos, sobre todo triangulares, con retoques simples o planos, inversos o bifaciales en la base. Este fenómeno se produce durante el VII Milenio BP, y está representado en los yacimientos de El Pontet-c, Els Secans-II, Botiquería-IV y Costalena $\mathrm{c} 3 / \mathrm{c} 2$. Los triángulos con espina central aparecen en momentos inmediatamente anteriores a la cerámica (Cava, 1994).

\section{Proceso neolitizador}

La evolución tardía del geometrismo coincide con las primeras manifestaciones neolíticas. La cronología de este proceso es variable, y las manifestaciones más características se encuentran en los yacimientos más orientales. En la mitad occidental se introducirán algunos elementos de cultura material Neolíticos hacia mediados del VII Milenio BP. En los yacimientos del Bajo Aragón los trapecios se reducen al mínimo. Los segmentos irrumpen junto con un sensible aumento de los triángulos, el retoque bifacial sustituye al abrupto y disminuye la técnica del microburil. En los yacimientos de la mitad occidental se mantienen los tipos anteriores, aunque a veces se localizan segmentos y triángulos de doble bisel. Con el cambio en la economía de producción disminuyen los geométricos y aparecen hojitas troceadas con retoque simple, que muestran en los análisis traceológicos huellas de faenas agrícolas (Cava, 1994).

\begin{tabular}{|c|c|}
\hline Último tercio IX Milenio BP & Epipaleolítico de ascendencia lamina \\
\hline VIII ${ }^{\circ}$ Milenio BP & Desarrollo de facies geométrica \\
\hline Segundo tercio $\mathrm{VII}^{\circ}$ Milenio BP & Primeras cerámicas \\
\hline
\end{tabular}

La evolución de los elementos geométricos hallados en los distintos yacimientos de la Cuenca del Ebro se articula de la siguiente manera (Barandiarán y cava, 1990):

- Sustitución progresiva de trapecios por triángulos conforme se avanza en el tiempo; los trapecios dominan durante el Epipaleolítico; los triángulos durante el Neolítico;

- Sustitución progresiva del retoque abrupto por el de doble bisel, propio del Neolítico;

- Asociación preferente de trapecios con retoque abrupto y de triángulos con retoque en doble bisel; 
- Desarrollo tardío de los segmentos de círculo, en general asociados al retoque en doble bisel;

- Aparición esporádica en momentos concretos de algunos tipos característicos, como los triángulos tipo Cocina;

- Se distinguen al menos dos áreas territoriales que siguen distintos modelos de evolución de las industrias geométricas:

- Oriental. Yacimientos semejantes al área Levantina, donde se aprecia una clara evolución del Epipaleolítico al Neolítico en la industria lítica o una incidencia profunda en la neolitización (Botiquería, Costalena y Chaves).

- Occidental. Desarrollo del geometrismo durante el Mesolítico o el Neolítico. Evolución de tipos y técnicas diferente a la de la zona oriental (La Peña, Fuente Hoz, Montico de Charratu, Zatoya).

El microburil es un elemento ligado a la fabricación de geométricos con retoque abrupto; con la llegada del Neolítico y la generalización del retoque de doble bisel, estos elementos desaparecen del registro arqueológico (Barandiarán y Cava, 1989).

\section{CRONOLOGÍA}

La mayoría de las dataciones pertenecientes al Magdaleniense Superior se concentran en momentos anteriores al $12.000 \mathrm{BP}$. Encontramos en este XIII Milenio un claro solapamiento entre el Magdaleniense Superior y el Epimagdaleniense, que continúa en el siguiente Milenio (XII), pero invirtiendo los papeles, es decir, dominando ahora el Epimagdaleniense sobre el Magdaleniense Superior.

En el País Valenciano se conocen conjuntos datados a finales del XII Milenio BP atribuidos ai Magdaleniense Superior que por su estructura tipológica podrían ser considerados como Epipaleolíticos (Aura y Villaverde, 1995).

La única datación de Murcia, la de la Cueva del Caballo, ha sido atribuida a un conjunto del Magdaleniense Superior; sin embargo es coetánea de las series Epipaleolíticas de Valencia y Andalucía (Aura y Villaverde, 1995).

La frontera entre el Magdaleniense Superior Final y el Epipaleolítico es verdaderamente difusa: parece detectarse en la industria, a grandes rasgos, un aumento de los raspadores en detrimento de los buriles. Pero ésto 
no se detecta, ni mucho menos, en todas las colecciones; el cambio, de existir, es tan sutil que es casi inapreciable.

El siguiente Milenio (XI) parece estar protagonizado por un lado por el Epipaleolítico Inicial y el Aziliense, este último sobre todo en los yacimientos del Valle del Ebro, y por la aparición de los primeros geométricos exclusivamente en la zona catalana. Este geometrismo está dominado por los triángulos, por influencia del Sauveterroide llegado de Francia, corriente que no sobrepasa el río Ebro. Este geometrismo catalán se concentra especialmente en el X Milenio, contraponiéndose al resto de las áreas estudiadas, donde persisten las industrias de clara tradición Paleolítica.

En Cataluña entre 11.500 y 10.000 BP existen conjuntos atribuidos al Magdaleniense Superior Final, al Aziliense, al Epipaleolítico Microlaminar, al Epipaleolítico Geométrico/Sauveterriense y al Mesolítico (Aura y Villaverde, 1995).

A partir del X Milenio BP se constatan algunas diferencias regionales, como la aparición de una facies Sauveterriense en el Epipaleolítico Geométrico del territorio catalán o una perduración del Epipaleolítico Microlaminar Mediterráneo hasta el $9.000 \mathrm{BP}$ al sur del Ebro (Aura y Villaverde, 1995).

A lo largo del IX Milenio se aprecia el pleno desarrollo del geometrismo, no sólo en Cataluña, sino también en el resto de la Vertiente Mediterránea y el Valle del Ebro. Paralelamente se desarrollan otras industrias de aspectos igualmente avanzado, alejadas de el sustrato Paleolítico hasta ahora dominante, pero con escasas o ninguna armadura geométrica. Este Epipaleolítico Final perdurará hasta el final del VIII Milenio, momento en que parece entrar en contacto con la neolitización, apreciándose ahora rasgos de aculturación e innovaciones en la cultura material, como la aparición de la cerámica o la generalización del retoque a doble bisel.

Para cada división cultural parece existir un momento central que concentra el mayor número de dataciones. La cronología del Epipaleolítico de la vertiente Mediterránea de la Península lbérica puede resumirse de la siguiente manera:

$\begin{array}{cc}\text { Magdaleniense Superior } & \text { Hasta XIII Milenio } \\ \text { Epimagdaleniense } & \text { XII Milenio } \\ \text { Epipaleolítico Inicial } & \text { XI y X Milenios } \\ \text { Epipaleolítico Geométrico } & \text { X Milenio } \\ \text { Sauveterroide en Cataluña } & \text { IX y VIII Milenios } \\ \text { Epipaleolítico Final, Mesolítico y EGM } & \text { VIII y VII Milenios } \\ \text { Inicio de la neolitización } & \end{array}$




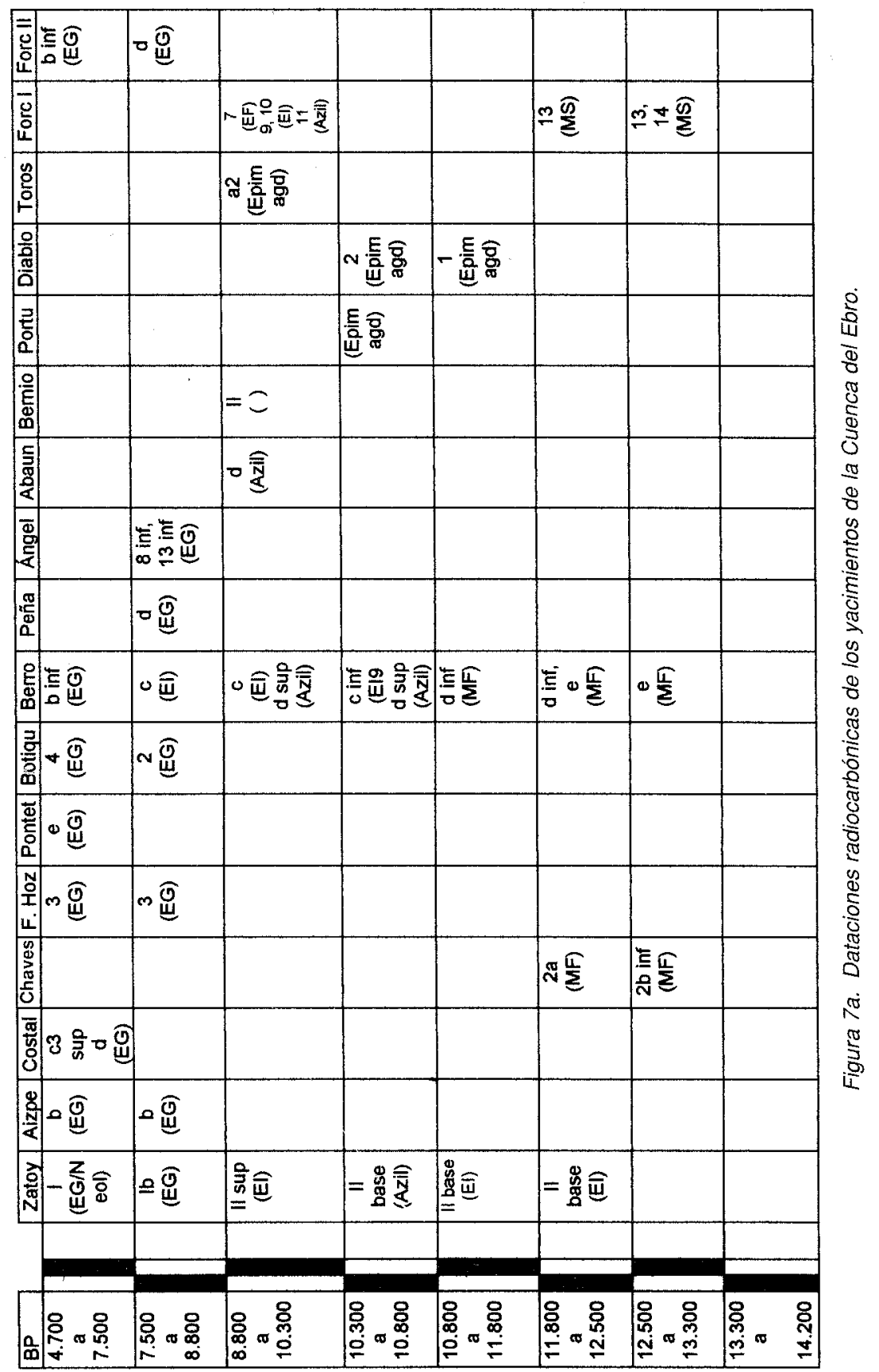


El Epipaleolítico en la vertiente mediterránea de la Península lbérica...

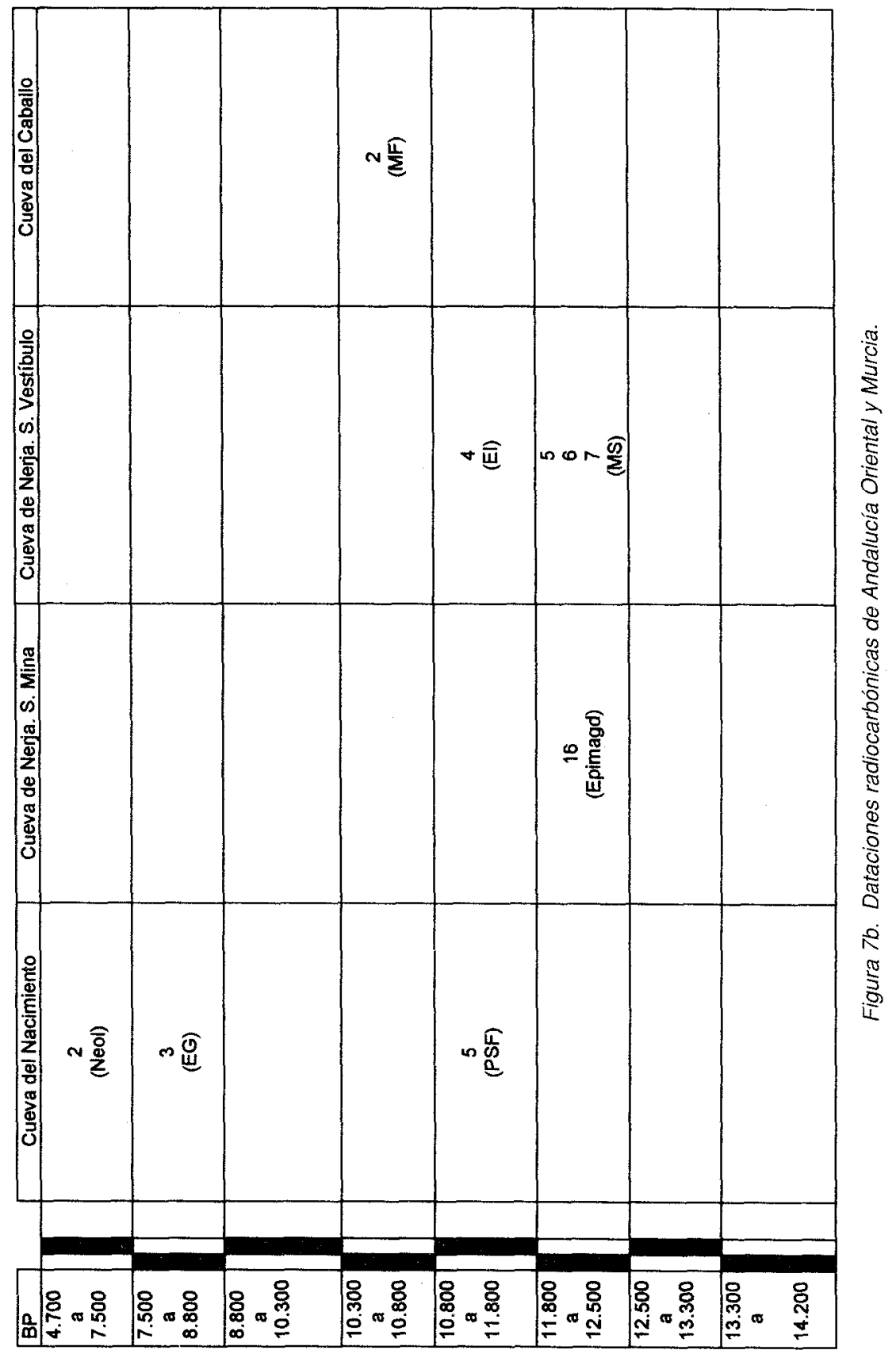




\begin{tabular}{|c|c|c|c|c|c|c|c|c|}
\hline 일 & & To & & & & & & \\
\hline 줄 & 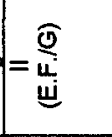 & & & & & & & \\
\hline$\frac{\mathscr{3}}{\mathrm{d}}$ & $\begin{array}{l}=\overline{\bar{d}} \\
-\dot{\Phi}\end{array}$ & & & & & & & \\
\hline$\frac{0}{\frac{5}{0}}$ & & $\geq \stackrel{\widehat{\bar{d}}}{\gtrless}$ & & & & & & $\rho \stackrel{\overline{0}}{\underline{N}}$ \\
\hline ¿ू & & & & & & & $=\frac{\stackrel{\mathrm{g}}{\mathrm{g}}}{\stackrel{\mathrm{E}}{\mathrm{W}}} \equiv \frac{\widehat{D}}{\mathrm{w}}$ & $\equiv \frac{\widehat{D}}{\Sigma}$ \\
\hline 号 & & & & & 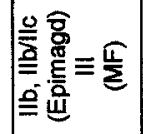 & 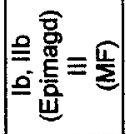 & 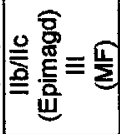 & $\equiv \frac{\mathbb{T}}{2} \geq \frac{\widehat{2}}{2}$ \\
\hline 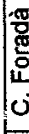 & & & & & 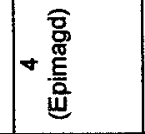 & $r \frac{\mathbb{1}}{\Sigma}$ & & \\
\hline 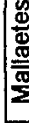 & & & & 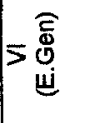 & & & & \\
\hline 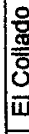 & & 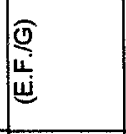 & & & & & & \\
\hline $\begin{array}{l}8 \\
0 \\
1-1\end{array}$ & & 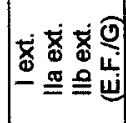 & 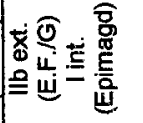 & & & 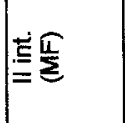 & 咅焉 & $\sum \frac{\tilde{\Xi}}{\Sigma}$ \\
\hline & $\left\{\begin{array}{l}\infty \\
2 \\
2 \\
-\frac{\dot{\bar{d}}}{2}\end{array}\right.$ & $\cong=\frac{\widehat{0}}{2}$ & 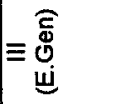 & & & & & \\
\hline & & & & & & & & \\
\hline & $\underset{\substack{8\\
}}{8}$ & 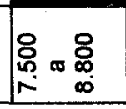 & $\begin{array}{l}8 \\
\substack{\infty \\
\infty \\
\infty} \\
0\end{array}$ & 啹 & $\begin{array}{ll}8 & 8 \\
0 & 0 \\
0 & \approx \\
\end{array}$ & 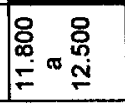 & 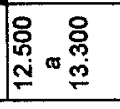 & 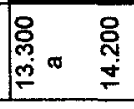 \\
\hline
\end{tabular}


El Epipaleolítico en la vertiente mediterránea de la Península Ibérica...

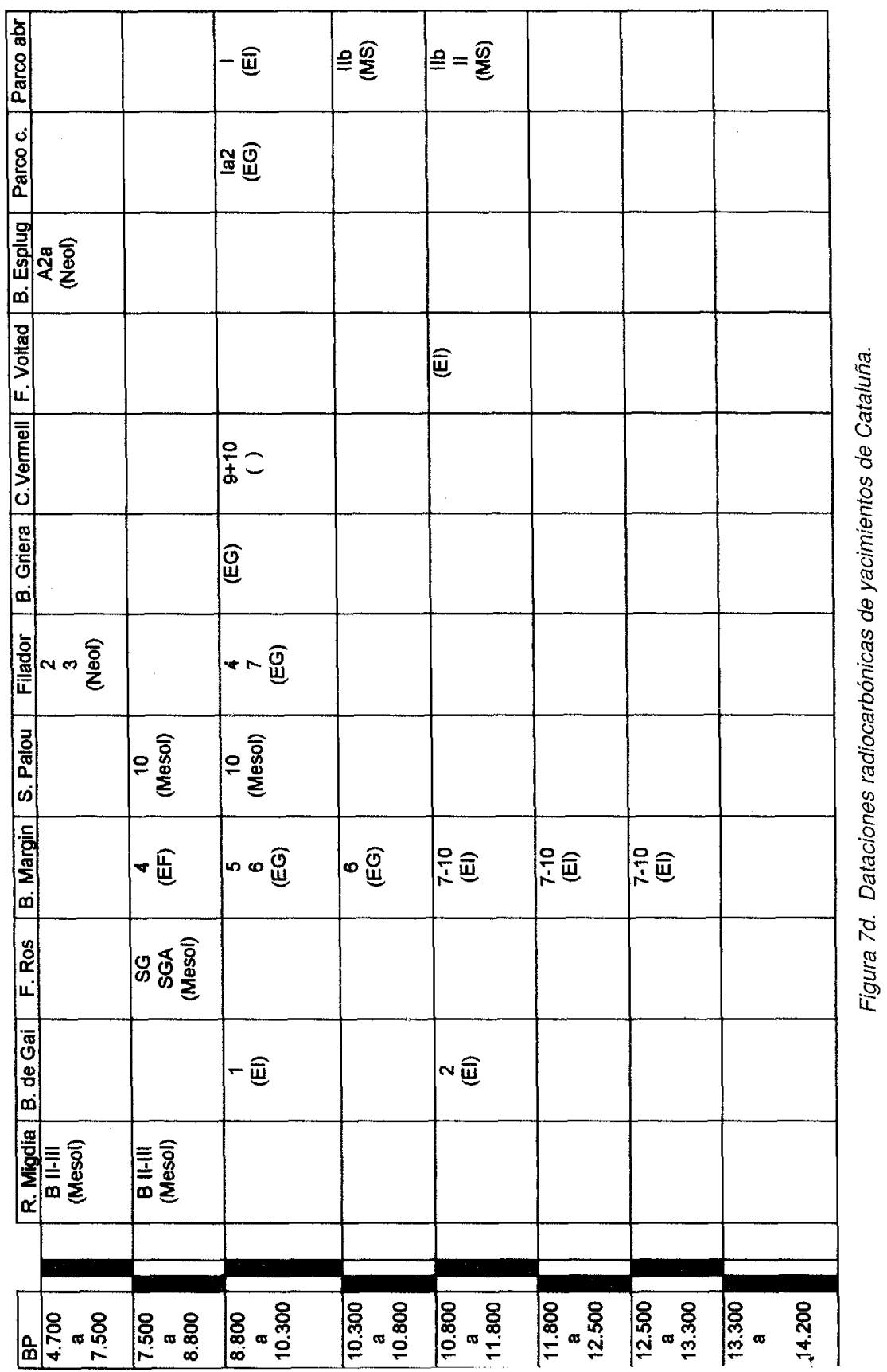




\section{CONCLUSIONES}

Llamamos Epipaleolítico al momento cronocultural desarrollado entre el Magdaleniense y el Neolítico. Podemos establecer una diferencia clara entre el Epipaleolítico y el Neolítico: el cambio principal se da en la economía de subsistencia, con el Neolítico aparece la producción de alimentos. Sin embargo es muy difícil hallar un elemento diferenciador claro entre el Magdaleniense y el Epipaleolítico. Si nos centramos en las cuestiones económicas, como lo hacemos para el límite final del período, encontramos que las diferencias son prácticamente imperceptibles o producto de una lentísima evolución; si buscamos la diferenciación en la industria tenemos el mismo problema, al que además hay que añadir la enorme diversificación industrial del Magdaleniense Mediterráneo. Miremos hacia donde miremos, las analogías entre lo que llamamos Magdaleniense Final y lo que llamamos Epipaleolítico Inicial, Microlaminar o Epimagdaleniense son tales que nos hacen dudar si no estamos hablando de lo mismo.

La única característica que parece que no ofrece ningún tipo de duda es la desaparición del gran Arte Paleolítico, con gran auge durante el Magdaleniense y que deja de existir de forma radical. Parece que podemos analizar este hecho de una forma global, como drástico elemento diferenciador entre los dos períodos; sin embargo es imposible aplicar esta característica para diferenciar ambos momentos de una forma particular. No podemos aplicar la no existencia de arte para realizar una adscripción cultural. De esta forma tanto los indicios económicos como los industriales y los artísticos quedan reducidos a aspectos globales y no particulares a la hora de establecer secuencias cronoculturales, y no tienen la capacidad de distinguir por sí mismos uno u otro período.

Restaría, por tanto, crear un espacio en el que tengan importancia las dataciones relativas y absolutas. Por sí mismas tampoco van a darnos la solución: las dataciones relativas sólo pueden ser contrastadas una vez hayamos analizado todos los procesos postdeposicionales que puedan haber alterado el registro, tarea no siempre fácil, incluso en muchas ocasiones excesivamente complicada en cuanto a su evaluación. En cuanto a las dataciones radiocarbónicas, aparte del riesgo de contaminación y toma de muestras contamos con las diferencias que pueden resultar de los análisis efectuados en distintos laboratorios o con diferentes métodos. Sin embargo, a pesar del gran margen de error que ofrecen, pensamos que puede ser un elemento válido a la hora de establecer una sistematización basada en secuencias cronoculturales.

El estudio de la industria lítica no puede ser el objetivo final de nuestro trabajo. Es mucho más importante comprender los estadios evolutivos, sociales y económicos de una determinada cultura; el medio ambiente en que se desarrolló, cómo interactuaron los grupos humanos con el medio, etc. No podemos 
limitarnos a crear «facies» a partir de la presencia, ausencia o porcentaje de un determinado instrumento lítico, los estudios tecnológicos y tipológicos del material lítico son sólo uno de los medios que tenemos para conocer la historia global, únicamente son una de las fases del estudio que no puede por sí misma ofrecer, como ninguna otra puede, una visión global de una cultura.

A diferencia de lo que ocurre en otros períodos prehistóricos, en el Epipaleolítico de la Vertiente Oriental de la Península lbérica asistimos a un proceso casi simultáneo (en líneas generales) en el que detectamos diferencias con la tradición anterior, aunque sin separarse de ella. Sabemos que hay variaciones en la industria, en la economía y el mundo ideológico, caracterizado en el arte. Sabemos también que en el mismo periodo se dan una serie de cambios ambientales, lo cual es una característica importante, pero no la causa principal de ese cambio. El cambio, además, es tan paulatino que resulta extremadamente difícil, si no imposible, fijar momentos transicionales. Resulta difícil; incluso, establecer las características que definen ese cambio, ya que casi todas las que podemos alegar los encontramos en momentos precedentes. Sin embargo la conjunción de todos estos factores (desaparición del arte, cambio paulatino en porcentajes y tipos industriales, cambios medioambientales, ligerísimo y paulatino cambio en explotación de los recursos-diversificación) nos da como resultado a lo largo del tiempo una realidad cultural, el Epipaleolítico, distinta a la anterior, el Paleolítico Superior.

El verdadero cambio industrial se produce con la irrupción de los geométricos, las llamadas influencia Sauveterrienses y Tardenoisienses. Todo lo tradicionalmente definido como Epipaleolítico Microlaminar Mediterráneo no corresponde más que a una continuación del Paleolítico Final. Como ya adelantaran otros autores (E. Aura, C. Cacho, etc.) nos encontramos en realidad con una continuación tanto en base industrial como en explotación de recursos y relación con el medio prácticamente idéntica a la del Magdaleniense, aunque con algunos cambios, muy paulatinos y lógicos por otro lado, ya que en un período tan largo éstos han de darse, ya sean por causas medioambientales, demográficas o ambas unidas. Aunque no podemos seguir hablando de Magdaleniense, ya que es evidente que no es exactamente lo mismo, tampoco podemos hablar de otro período distinto, y menos en razón a las variaciones tipológicas. El mayor o menor porcentaje de ciertos tipos puede deberse a muchos factores, entre ellos la diversa funcionalidad o condicionamientos dados por la abundancia o escasez de la materia prima. Sea cual sea el término que utilicemos, Epipaleolítico o Epimagdaleniense, estamos hablando de las mismas gentes, con la misma tradición industrial e idéntica relación con el entorno, aunque con pequeños cambios.

Sin embargo con la irrupción del geometrismo sí podemos utilizar el término Epipaleolítico haciendo referencia a una serie de cambios industriales y muy 
posiblemente también culturales y de relación con el medio claros, que recibe otras influencias distintas a las anteriores y que acabará optando por una economía de producción. Si esto es cierto, no podemos aceptar la existencia de la facies Mallaetes de Fortea, ya que sería suponer que el Epimagdaleniense continúa desarrollándose en este yacimiento sin apenas cambios a lo largo de, al menos, dos milenios y sin entrar en contacto con zonas ni yacimientos vecinos, constituyendo un núcleo aislado y autosuficiente que no deja pasar una sola influencia hasta la llegada de un Neolítico plenamente formado, dándose así un paso directo del Epipaleolítico al Neolítico. Actualmente ésto resulta increíble. Necesariamente tiene que existir un hiatus ocupacional entre el Epipaleolítico y los niveles cerámicos de Mallaetes que en su día no fue reconocido o que no ha dejado una huella clara en el registro geológico.

Las causas de la implantación del Epipaleolítico pueden proceder de diversos factores (Martínez Andreu, 1989/90):

- Tendencia a suavizarse las condiciones climáticas con la llegada del Holoceno, con un aumento de las temperaturas, aunque no es creíble que las razones climáticas fueran las únicas causas.

- Un progresivo agotamiento del ecosistema unido a unas condiciones climáticas adversas impondrían un modelo de concentración del territorio

- Un aumento demográfico no controlado implicaría una serie de reajustes sociales, una mayor dificultad en la movilidad y una explotación de recursos más concentrada.

- La larga experimentación tecnológica y la especialización son motivos suficientes para imponer paulatinamente una mayor sedentarización, que requeriría un aprovechamiento más variado y exhaustivo del territorio.

- Los datos del registro arqueológico indican al final del Paleolítico la existencia de un modelo económico basado en la caza y la recolección, pero demostrando una explotación más diversificada del medio ambiente con estrategias amplias, en las que el mar empieza a desempeñar un papel importante entre las poblaciones relacionadas con la costa.

- La diversificación de los recursos posibilitaría cierta estabilidad que con el tiempo se convertirá en un estilo de vida sedentario.

\section{PROPUESTA DE SISTEMATIZACIÓN DEL EPIPALEOLÍTICO DE LA MITAD ORIENTAL DE LA PENÍNSULA IBERRICA}

El Epipaleolítico de la Mitad Oriental de la Península Ibérica (figura 8) cuenta con unas características particulares que permiten su división en tres momentos en función de la cronología y de los restos materiales: 


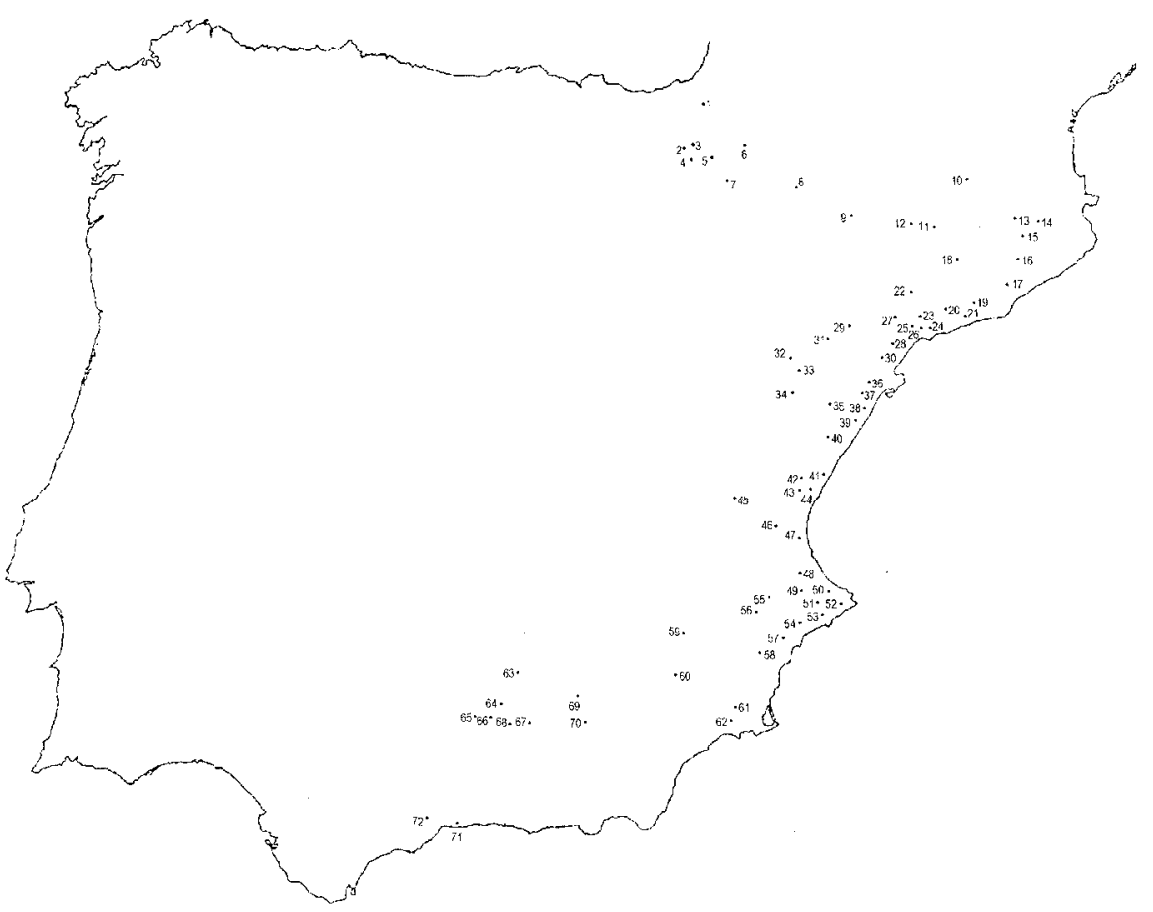

Figura 8. Yacimientos Epipaleoliticos de la Vertiente Oriental de la Península lbérica:

1. Sorgiñen Leze

2. Fuente $\mathrm{Hoz}$

3. Montico de Charratu

4. Abauntz

5. Berroberria

6. Zatoya

7. Padre Areso

8. Chaves

9. Forcas

10. Balma Margineda

11. Sota Palou

12. Cova del Parco

13. Sant Benet

14. Coma d'infern

15. Cingle Vermell

16. Balma de l'Espluga

17. Roc del Migdia

18. Balma de Gai

19. Font del Ros

20. Cova de la Guineu

21. Balma de la Griera

22. Bauma de la Peixera d'Alfés

23. Font Voltada

24. Cova dels Colls
25. Hort d'En Marquet

26. Hort de la Boquera

27. Filador

28. Sant Gregori

29. Botiquería dels Moros

30. La Mallada

31. Costalena

32. Ángel

33. Peña del Diablo

34. Cueva de los Toros

35. Cova Fosca

36. Pla de la Pitja

37. Matutano

38. Corral Blanc

39. Raca

40. Cova dels Blaus

41. La Cova

42. Balsa de la Dehesa

43. Can Ballester

44. Estany Gran

45. Verdelpino

46. El Prat

47. Volcán del Faro

48. El Collado
49. Barranc de les Calderes

50. Cova Fosca

51. Coves d'Esteve

52. Cendres

53. Tossal de la Roca

54. Abric de la Falguera

55. Santa Maira

56. Cova Bernat

57. Cova del Mas Gelat

58. Cueva del Lagrimal

59. Molino Vadico

60. Ambrosio

61. Cueva del Algarrobo

62. Cueva del Caballo

63. Olivar de las Patudas

64. Fuente del Carmen

65. Fuente del Pez

66. El Pirulejo

67. Fuente de las Palomas

68. Llanos de Jarcas

69. Nacimiento

70. Valdecuevas

71. Nerja

72. El Duende 
- El Epimagdaleniense, heredero directo del Magdaleniense Superior.

- El Epipaleolítico Genérico Inicial, continuación del anterior.

- El Epipaleolítico Final, que muestra tres grupos industriales distintos, pero contemporáneos:

- El Epipaleolítico Geométrico, ya descrito por J. Fortea.

- El Epipaleolítico Avanzado sin geométricos.

- El Epipaleolítico Atípico, que llamaremos Mesolítico respetando la nomenclatura utilizada por otros autores.

El Epimagdaleniense deriva directamente del Magdaleniense Superior. Básicamente es idéntico en cuanto a explotación de recursos e industria a ese período. Sin embargo la diferencia existe. Como antes adelantamos, la desaparición del Arte Rupestre Paleolítico constituye por sí mismo un hito, aunque en muchas ocasiones no evaluable, suficientemente significativo para caracterizar un cambio cultural.

En líneas generales las características industriales se pueden definir por la casi desaparición de la industria ósea y en cuanto a la lítica por un desequilibrio inverso al del Magdaleniense en la relación entre raspador/buril, que suele ser equilibrada o favorable a los primeros. También suelen alcanzar porcentajes importantes las piezas de dorso, especialmente las hojitas, y las truncaturas retocadas. La industria es esencialmente laminar y de pequeñas dimensiones. Todas las características industriales están directamente relacionadas con los momentos anteriores. Las variaciones son, en muchas ocasiones, imperceptibles.

En cuanto a la explotación de los recursos, prácticamente no encontramos variación con los momentos precedentes. Tal vez se detecte una ligera ampliación de los recursos, circunstancia debida a las variaciones climáticas iniciadas ya tiempo atrás.

Donde se detectan mayores cambios es en los lugares de ocupación, que parecen diversificarse; se ocupan sitios hasta entonces no habitados, ésto es especialmente evidente en el Valle del Ebro. Incluso empiezan a incrementarse las ocupaciones al aire libre.

Este período, muy solapado con el Magdaleniense Superior y muy difícil de distinguir de éste, se desarrolla a lo largo del XII Milenio, como demuestran los siguientes yacimientos ${ }^{2}$ :

2 Existen muchos más yacimientos clasificables dentro de este período. Sin embargo para realizar esta sistematización sólo contamos con los yacimientos que presentan una estratigrafía 
Tossal de la Roca (Vall d'Alcalà, Alicante). Nivel I, corte interior.

Cendres (Teulada, Alicante). Nivel II.

Coves d'Esteve (Vall d'Ebo, Alicante).

Cova Fosca (Vall d'Ebo, Alicante). Niveles III y IV.

Cova Matutano (Vilafamés, Castellón). Niveles IA y IB.

Cueva del Algarrobo (Mazarrón, Murcia). Nivel 1.

Cueva de Chaves (Bastarás, Huesca). Nivel 1c.

El que hemos denominado como Epipaleolítico Genérico Inicial se encuentra plenamente desarrollado durante el $\mathrm{Xl}$ y el $\mathrm{X}$ Milenios. Las diferencias con el período anterior no son muy evidentes. En general se puede decir que se exageran las tendencias observadas durante el Epimagdaleniense: se aprecia una mayor diversificación en la explotación de los recursos, así como una incipiente tendencia si no todavía a la sedentarización sí a una menor movilidad. Los cambios son extremadamente paulatinos, como viene sucediendo desde tiempo atrás. La diferencia fundamental reside en la cronología, puesto que ya no se produce el solapamiento con el Magdaleniense Superior.

Las características industriales de este período son básicamente las mismas que las del anterior, tal vez algo más marcadas, aunque con una enorme variabilidad dentro de los diferentes conjuntos. Los grupos predominantes suelen ser los raspadores y las hojitas de dorso. También son abundantes las puntas de dorso. Los buriles suelen presentar porcentajes moderados, aunque son también muy variables. Empiezan a cobrar importancia los útiles de sustrato, especialmente las muescas y denticulados, que suelen ser más numerosos según avanzamos en el tiempo, quizá como preludio a lo que ocurrirá en la siguiente etapa.

La relación con el medio viene caracterizada por el mayor número de recursos explotados. La ocupación del espacio continúa también la tendencia del momento anterior, generalizándose aún más los asentamientos al aire libre y ocupando numerosos yacimientos de nueva planta. Tal vez ésto sea producto de una menor movilidad y una mayor presión demográfica.

Los yacimientos que caracterizan este período son los siguientes:

Cueva del Lagrimal (Villena, Alicante). Nivel IV.

Cueva de Santa Maira (Castell de Castells, Alicante). Nivel IV y V.

susceptible de ser comparada y en la que se puedan analizar los procesos deposicionales. Lo mismo ocurrirá con los yacimientos elegidos para sistematizar los siguientes períodos. 
Cova de la Guineu (Font Rubí, Tarragona).

El Filador (Margalef del Montsant, Tarragona). Estratos 8, 9 y 10.

Cueva de Nerja (Maro, Málaga). Vestíbulo, nivel IV; Mina, nivel XII y XIII.

Molino Vadico (Yeste, Albacete). Niveles B, C y D.

Cova del Parco (exterior) (Alós de Balaguer, Lérida). Nivel lla y Illb.

El Epipaleolítico Final es tal vez el período mejor conocido desde hace tiempo. Adquiere una especial relevancia en la zona del valle del Ebro. Las tres facies en que lo hemos dividido presenta importantes diferencias en la industria lítica, pero no en el resto de los factores.

El Epipaleolítico Geométrico fue ya definido por Fortea. Es el más temprano, al menos en la zona catalana, donde empieza a desarrollarse durante el $\mathrm{X}$ Milenio, momento en que en el resto de las áreas está plenamente implantado el Epipaleolítico Inicial. La industria de este momento se caracteriza por la abundancia de triángulos, de clara tradición Sauveterroide, influencia debida a la cercanía y comunicación del área catalana con la francesa. Este geometrismo Sauveterroide no sobrepasa la frontera establecida por el Ebro, sino que el geometrismo que se desarroIlará en los dos siguientes milenios, IX y VIII, tendrá un matiz distinto, la industria estará dominada en primer lugar por los trapecios y posteriormente por triángulos y segmentos. Junto con las armaduras geométricas que caracterizan esta industria adquieren gran importancia las muescas y denticulados, así como la técnica de microburil.

El que hemos denominado Epipaleolítico Atípico o Mesolítico presenta una industria distinta, en la que los tipos dominantes suelen ser las raederas y las muescas y denticulados. Normalmente esta diferencia en la industria se debe a la utilización de materias primas más bastas que el sílex, como la caliza o la cuarcita.

En la industria del Epipaleolítico Genérico Final el elemento más importante es el de las muescas y denticulados. No contienen geométricos, o éstos son tan escasos que no llegan a considerarse en los estudios tipológicos. Son comunes también las raederas, elementos de dorso, lascas retocadas y piezas de estilo campiñense. Estos últimos tipos son comunes también en las industrias geornétricas.

La industria lítica es ligeramente distinta en unos y otros grupos, sin embargo los tres muestran las mayores analogías en lo que se refiere a la explotación del medio, del hábitat y en el período cronológico en el que se desarrollan, entre el IX y VIII Milenio (excepto el caso catalán, que ya hemos comentado que es más temprano). 
Los asentamientos son cada vez más sedentarios. Se buscan recursos estables, para lo que se necesita una mayor ampliación del espectro. Culmina así un proceso iniciado hace tiempo. Se intensifica especialmente la recolección vegetal. El avellano, que se extiende en este período a causa de la bonanza climática, adquiere gran importancia en la alimentación de estos grupos, aún cazadores-recolectores.

El Epipaleolítico Final constituye el sustrato que más adelante acogerá a la neolitización como nuevo modo de vida. La progresiva sedentarización y la explotación de cada vez más amplios recursos llevarán al medio ideal para el cambio a la economía productora.

Los yacimientos que caracterizan este período son los siguientes:

\section{Epipaleolítico geométrico:}

Abric de la Falguera (Alcoi, Alicante). Nivel II y III.

Tossal de la Roca (Vall d'Alcalá, Alicante). Corte exterior.

Balma de Gai (Moiá, Barcelona). Niveles c1, c2 y c3.

El Filador (Margalef del Montsant, Tarragona). Estratos 3, 4 y 7.

Cueva del Nacimiento (Pontones, Jaén). Nivel B.

Botiquería dels Moros (Mazaleón, Teruel). Nivel 4.

Costalena (Maella, Zaragoza). Nivel c3 y d.

Cueva del Parco (exterior) (Alós de Balaguer, la Noguera, Lérida).

Epipaleolítico Atípico o Mesolítico:

Font del Ros (Berga, Barcelona). Nivel c superior.

Roc del Migdia (Vilanova de Sau, Osona).

Sota Palou (Ripollés, Gerona).

Cingle Vermell (Vilanova de Sau, Barcelona).

\section{Epipaleolítico Genérico Final:}

Cova de Santa Maira (Castell de Castells, Alicante). Nivel III.

Cova Fosca (Ares del Maestrat, Castellón). Nivel III. 


\section{BIBLIOGRAFÍA}

Aura Tortosa, J.E. (1988): La Cova del Parpalló y el Magdaleniense medio de Facies lbérica o Mediterráneo. Propuesta de sistematización de la industria litica y ósea. Tesis doctoral. Universidad de Valencia.

Aura ToRtosa, J.E. (1992): "El Magdaleniense Superior Mediterráneo y su modelo evolutivo». En Utrilla (coord.): Aragón/Litoral Mediterráneo. Intercambios culturales durante la Prehistoria. Homenaje a D. Juan Maluquer de Motes. Instituto Fernando el Católico, pp. 167-177. Zaragoza.

Aura Tortosa, J.E. (1995): El Magdaleniense Mediterráneo: la Cova del Parpalló (Gandía, Valencia). SIP. Trabajos Varios, $n^{0} 91.216$ pp. Valencia.

Aura Tortosa, J.E.; Fernandez Peris, J.; Fumanal, M.P. (1993): "Medio físico y corredores naturales: notas sobre el poblamiento Paleolitico del Pais Valenciano". Recerques del Museu d'Alcol, ñII.

Aura Tortosa, J.E; PÉREz RIPOLL, M. (1992): «Tardiglaciar y Postglaciar en la región mediterránea de la Península lbérica (13.500-8.500 B.P.): transformaciones industriales y económicas". PLAV-Saguntum, $n^{\circ} 25$, pp. 25-47. Valencia.

aura Tortosa, J.E; Pérez Ripolt, M. (1995): «El Holoceno inicial en el Mediterráneo español (11.000-7.000 BP). Características culturales y económicas". En Villaverde (ed.): Los últimos cazadores. Transformaciones cuiturales y económicas durante el Tardiglaciar y el inicio del Holoceno en el ámbito mediterráneo, pp. 119-146. Instituto de Cultura Juan Gil-Albert. Diputación de Alicante.

Aura TORTOSA, J.E; VILLAVERdE BONILLA, V. (1995): «Paleolítico Superior Final y Epipaleolítico Antiguo en la España Mediterránea (18.000-9.000 BP)»: En Moure, A. y González Sáinz. C. (eds.): El final del Paleolítico Superior Cantábrico, pp. 313-340. Universidad de Cantabria.

Barandiarán, I. (1979): «El Epipaleolítico Geométrico en el bajo Aragón». XV Congreso Nacional de Arqueología, pp. 125-133. Zaragoza, 1977.

BARANDIARÁN, 1. (1995): “Los establecimientos de cazadores de la Prehistoria de Navarra. Del Paleolítico Medio a inicios del Neolítico". Cuadernos de Arqueología de la Universidad de Navarra, $n^{\circ} 3$, pp. 53-87. Pamplona.

Barandiarán, 1.; Cava, A. (1985): "Las industrias líticas del Epipaleolítico y del Neolítico en el Bájo Aragón". Bajo Aragón, prehistoria, n² 5 . Zaragoza.

BarandiarÁn, I.; CAVA, A. (1989): La ocupación prehistórica del abrigo de Costalena (Maella, Zaragoza). $164 \mathrm{Pp}$. Colección Arqueología y Paleontología, $n^{\circ} 6$. Diputación General de Aragón.

BarandiarÁN, I.; CAVA, A. (1990): “The evolution of the Mesolithic in the North East of the Iberian Peninsula». En Bonsall, C. (ed.): The Mesolithic in Europe. John Donald,Itd., 1985, pp. 572-581. Edinburgh.

Bernabeu, J.; Aura, J.E.; Badal, E. (1993): Al Oeste del Edén. Editorial Síntesis.

CACHO QUESADA, C. (1989): "Structuration du Magdalenien dans l'Espagne Méditerranéenne». En Rigaud, J.Ph. (ed.): Le Magdalenien en Europe. La structuration du Magdalénien. Actes du Colloque du Mayence, 1987. Eraul, nº 38, pp. 459-476. Liëge.

Cacho Quesada, C.; Fumanal, M.P.; López, P. (1983): «Contributión du Tossal de la Roca a la chronostratigraphie du Páleolithique Superieur Final dans la region de Valence (Espagne)". La possition taxonómique et chronologique des industries á pointes á dors autour de la Mediterranée. Rivista di Scienze Preistoriche, Volumen XXXVIII, Fasc. 1-2, pp. 69-90. Firenze.

Cava Almuzara, A. (1994): «El Mesolitico en la Cuenca del Ebro. Un estado de la cuestión». Zephyrus, n47, pp. 65-91. Salamanca.

Cóndoea, B.; Vega Toscano, L.G. (1985): «El Paleolítico de la Sierra del Segura: proyecto de investigación". En Pueblos y culturas prehistóricas y protohistóricas (1). 1ํ Congreso de Historia de Castilla-La Mancha, tomo II, pp. 79-85.

DOMENECH, E.M. (1990): "Aportaciones al Epipaleolítico de la Provincia de Alicante". Resumen de la tesis de licenciatura. Alberri, $n^{\circ} 3$, pp. 15-166. Concentaina, Alicante.

FORTEA, J. (1973): Los complejos microlaminares y geométricos del Epipaleolítico mediterráneo español. Memorias del seminario de Prehistoria y Arqueología, $n^{\circ} 4.550$ pp. Universidad de Salamanca. 
Garcia Argüelles, P.; Adserias, M.; Bartrolí, R.; Bergadá, M.; Cebrià, A.; Doce, R.; Fullola, J.M.; NADAL, J.; RIBÉ G.; RODÓn, T.; VIÑAS, R. (1992): "Síntesis de los primeros resultados del programa sobre Epipaleolítico en la Cataluña Central y Meridional». En Utrilla, P. (coord.): Aragón/Litoral Mediterráneo. Intercambios culturales durante la Prehistoria, pp. 269-248. Zaragoza.

GutiÉRREz EloRzA, M. (Coord.) (1994): Geomorfología de España. Ed. Rueda. Madrid.

JuAn CABANILles, J. (1985): «El complejo Epipaleolítico Geométrico (facies Cocina) y sus relaciones con el Neolítico Antiguo". P.L.A.V. Saguntum, no 19, pp. 9-30. Valencia.

Martinez Andreu, M. (1989-90): «Síntesis del Epipaleolítico en el Levante y sur peninsular. Antecedentes y estado actual de la cuestión». Anales de Prehistoria y Arqueología, no 5-6, pp. 49-58. Universidad de Murcia.

OLARIA, C.; GusI, F.; Estévez, J.; CASABÓ, J.; RoVIRA, M.L. (1981): «El yacimiento Magdaleniense Superior de Cova Matutano (Villafamés, Castellón). Estudio del sondeo estratigráfico de 1979". Cuadernos de Prehistoria y Arqueología Castellonense, no 8, pp. 21-100. Castellón.

UtRillA, P.; MAZO, C. (1994): «El poblamiento prehistórico del Valle del río Esera (Ribagorza, Huesca)». Bolksan, no 11, pp. 53-68. Instituto de estudios Altoaragonenses. Diputación de Huesca.

VillaVerde Bonilla, V. (1984): "La industria Magdaleniense de l'Abric de la Senda Vedada (Sumacarcel, Valencia). Nuevas consideraciones sobre el Magdaleniense mediterráneo peninsular». P.L.A.V. Saguntum, $n^{\circ} 18$. Valencia.

Villaverde Bonilla, V. (1992): «El paleolítico en el País Valenciano». En Utrilla, P. (coord.): Aragón/Litoral Mediterráneo. Intercambios culturales durante la Prehistoria, pp. 55-88. Homenaje a J. Maluquer de Motes. Institución Fernando el Católico. Zaragoza.

Villaverde Bonilla, V.; Martínez Valle, R. (1995): "Características culturales y económicas del final del Paleolítico Superior en el Mediterráneo español». En VILLAVERDE, V. (ed.): Los últimos cazadores. Transformaciones culturales y económicas durante el Tardiglaciar y el principio del Holoceno en el ámbito Mediterráneo, pp. 79-118. Alicante. 